\title{
Group Play in Games and the Role of Consent in Network Formation
}

\author{
Gary Charness \\ Matthew O. Jackson
}

\begin{abstract}
We study games played between groups of players, where a given group decides which strategy it will play through a vote by its members. When groups consist of two voting players, our games can also be interpreted as network-formation games. In experiments on Stag Hunt games, we find that that the structure of the voting rule completely determines which equilibrium is played, independently of the payoff structure. Thus, we find a stark contrast between how groups and individuals play our games, with payoffs playing a much more important role in equilibrium selection in the latter case. We also explore play between groups where one member of each group dictates the play of that group. We find that the dictator tends to play a less risky strategy when choosing for a group than when playing only for him or herself.

We develop a new solution concept, robust-belief equilibrium, which explains the data that we observe. We provide results showing that this solution concept has application beyond the particular games in our experiments.
\end{abstract}

Keywords: Groups, Networks, Game Theory, Equilibrium Selection, Equilibrium Refinement, Majority Voting, Group Play, Robust-belief Equilibrium, Responsibility

JEL Classification Numbers: A14, C72, C91, D71, D72

Charness is at the Department of Economics, University of California Santa Barbara, Santa Barbara, CA 93106-9210, http://www.econ.ucsb.edu/ charness/, email: charness@econ.ucsb.edu; and Jackson is at the Division of the Humanities and Social Sciences, California Institute of Technology, Pasadena, California 91125, USA, http://www.hss.caltech.edu/ jacksonm/Jackson.html, email: jacksonm@hss.caltech.edu. Financial support from the Lee Center for Advanced Networking is gratefully acknowledged. 


\section{Introduction}

The decisions made by many social and economic organizations or groups involve some sort of consent. While classical models in economics treat firms as if they were individual decision makers, a firm generally comprises many agents who each have some input into the actions of the firm. In most organizations, some committee of members oversees the decisions of the organization and votes on critical decisions. There is typically some specified method of aggregating the agents' preferences into a group decision, and the nature of this method can have important consequences for the organization's behavior.

While it has long been recognized that treating firms and other organizations as individual decisions makers is at best an imperfect approximation, there is little that is known, theoretically, empirically, or experimentally, that discerns how groups interact compared to individuals. In this paper we look explicitly at the play of a game when the 'players' are actually groups of players. One of our main findings is that the play of games between groups of players is systematically different than games between individuals, even though all traditional game-theoretic equilibrium concepts do not provide any distinction in the games we examine. This prompts us to develop a new equilibrium concept to explain our observations.

To discuss our approach and analysis, it is easiest to fix ideas directly in terms of the game that we use in the experimental part of our study. Consider the following variation on Rousseau's classic Stag Hunt game.

\begin{tabular}{cccc} 
& & \multicolumn{2}{c}{ Player 2 } \\
& & Stag & Hare \\
\multirow{2}{*}{ Player 1 } & Stag & 9,9 & 1,8 \\
& Hare & 8,1 & 8,8
\end{tabular}

There are two Nash equilibria in pure strategies: one where both players play Stag, and another where both players play Hare. ${ }^{1}$

Let us consider the case where a 'player' is actually a couple. That is, there are two individuals who fill the role of a given player - and both of these individuals receive that player's 
payoffs. We now have to be explicit about how the couple determines whether to play Stag or Hare. There are different ways in which a couple could decide on how to play. The three prominent ones are:

- One of the two individuals dictates.

- The couple votes over which strategy to play by one of the following two methods:

-- It takes two votes for Stag to play Stag, and one vote for Hare to play Hare.

-- It takes one vote for Stag to play Stag, and two votes for Hare to play Hare.

Once we specify the method by which each couple makes the decision to play, the overall game is fully specified, so that we can solve for the equilibria of the larger four-player game. It is easy to see that regardless of the way in which the couples make their decisions, there will still be an equilibrium in which both couples play Stag, and another equilibrium in which both couples play Hare. In fact, it is clear that this is a much more general phenomenon: Any purestrategy equilibrium of a game with 'individual players' remains an equilibrium of the game where groups fill the roles of players, regardless of the way in which the groups make decisions. ${ }^{2}$

Given this observation, one might wonder whether there is anything interesting to learn about groups playing games in situations where each group's members share the same payoffs. We find that some equilibria are more pertinent when groups play than when individual players do, and that this selection among equilibria depends on the method by which the group makes decisions. We argue that there is a (formal) sense in which one of the two equilibria becomes more 'focal'. On an intuitive level this is quite easy to see. Suppose that both couples make decisions through a voting system where it takes two votes to play Stag and one vote to play Hare. In this situation, it is 'easier' for a couple to decide to play Hare. This in turn can feed into the expectations that one couple has about the other couple's play, and so forth. This leads to a prediction that the Hare equilibrium is the focal one in cases where it takes two votes to play Stag and one vote to play Hare. Correspondingly, the Stag equilibrium becomes more focal if the voting system is such that it takes two votes to play Hare.

\footnotetext{
${ }^{1}$ The selection between these equilibria (and those in related coordination games) has been the subject of much study. See for instance, Harsanyi and Selten (1988), Kandori, Mailath and Rob (2003), and the literature that followed.

${ }^{2}$ This is provided the group decision-making system has a full range. Specifying any actions that lead to the candidate strategy leads to a situation where no group member can benefit from a deviation.
} 
We come back to offer a formal analysis of this in Section 4, but for now let us take the view that the focal equilibrium play is the one which takes only one vote by either member of a couple to undertake.

\section{The Role of Responsibility in Group Play}

There are several considerations that go into an individual's decision in forming links or playing a game as part of a group. The individual has to forecast how the other group will behave. The individual also has to forecast how the other members of his or her group will behave. Beyond that, there can be a realization that one's actions have an impact on the payoffs of the other members of one's group. For instance, if an individual can form a link unilaterally, then an individual's decision can have an immediate impact on the partner's payoff without that partner having consented. How does being responsible for another person's payoffs influence behavior? Charness (2000) suggests that an agent with such responsibility will behave in a more 'pro-social' manner. Here, it is not completely obvious what 'pro-social' is, as there is not any sort of free-riding problem; however we might expect this to translate into playing a safer strategy when a non-enfranchised person's welfare is at stake than when all members of a group take part in the decision-making.

Sorting out this last question is a bit tricky since any consideration of such responsibility can become entangled with beliefs in the context of the play of a game. In order to see how feelings of responsibility might be influencing play, we ran two additional treatments in addition to the group-play treatments we have already described. The first was a control treatment in which there were just two players, one in each role. These games with individual players and no couples, served as a benchmark for all of our analysis. We also ran some additional games with a very simple variation designed to allow us to detect the role of responsibility. We introduced couples into the player roles, but only one individual in the couple made the decision: he or she was a dictator for the couple. If being responsible for another player's payoff had no effect on how individuals act, then the play in the benchmark treatment and 'couples with dictators' treatment should be exactly the same. If there is a significant difference, then it means that being completely responsible for another individual's payoff influences the way in which an individual plays a game. Indeed, as we shall see, this does influence play. 


\section{The Related Literature}

There are only a modest number of contributions from the economics and game theory literatures on games played by groups. ${ }^{3}$ From the theory side, Duggan (2001) defines "group Nash" equilibria and examines the group decision-making processes that allow for the existence of equilibrium when individuals in a group may have different payoff structures.

Experimentally, Cason and Mui (1997) consider individual and team choices in a dictator game, with group choices more generous than individual choices. In contrast, Cox (2002) finds that groups behave similarly to individuals as senders in an investment game, but send back much less. Blinder and Morgan (forthcoming) find that groups were just as quick as individuals to reach decisions and also outperform individuals. Cooper and Kagel (2003) study the behavior of individuals and two-player teams in signaling games; teams consistently play more strategically than individuals do. Similarly, Kocher and Sutter (forthcoming) find that groups learn more quickly than individuals in a beauty contest (guessing game).

Gary Bornstein and co-authors have a series of experimental papers on group play in social dilemmas, with particular emphasis on inter-group competition on group performance. Perhaps the most closely related paper is Bornstein, Gneezy, and Nagel (2002) who examine a variation of Van Huyck's (1990) minimum-effort game, where two groups play the game and only the group with the higher minimum receives a non-zero payoff (in the case of a tie, both groups earn half of this payoff). They find that such a form of inter-group competition leads to higher efforts and improved collective efficiency relative to the usual minimum-effort game.

In all of these games, groups either reach a unanimous decision after some form of communication or adopt the minimum (and therefore unanimous) choice. One paper that does consider a non-consensus aggregation rule is by Fréchette, Kagel, and Lehrer (2003), who examine amendment rules in legislative bargaining; while the distribution of benefits is rather egalitarian among winning coalition members, voters outside these coalitions receive little.

Our focus is on how the play of a game depends on the aggregation process of the individual choices in groups, and how this influences the beliefs and behavior of players. The structure of our games bears no resemblance to that in any of the papers mentioned above.

${ }^{3}$ As one would expect, the social-psychology literature has many studies of inter-group relations. Sherif (1966) and Tajfel (1982) provide extensive surveys of some of the classic theories of how groups interact. While this is a rich literature, we have not found any predictions that would help us select between the multiple equilibria in the games we study. 


\section{Network Formation and Consent}

Our analysis also has a completely different interpretation, and implications for a different area of study. In fact, our initial interest in this project originated from thinking about differences in protocols for network formation.

In many social and economic networks it takes the consent of both parties to maintain a link or tie. This includes such varied applications as friendships, political alliances, trading relationships, partnerships, etc. In some other contexts a tie can be formed unilaterally - one web site can link to another or one author can cite another, without having mutual consent. How does this difference in the consent needed to form a link affect the network that emerges?

Network formation maps directly to the analysis of the Stag Hunt as follows. The choice of play by a couple is whether or not to form a link. The 'voting rule' then translates into whether or not one needs the consent of both individuals to form a link or whether just one individual can form a link. For instance, consider starting at the following network, with corresponding payoffs to each one of the players. From here players can choose whether or not to add the missing links.

A

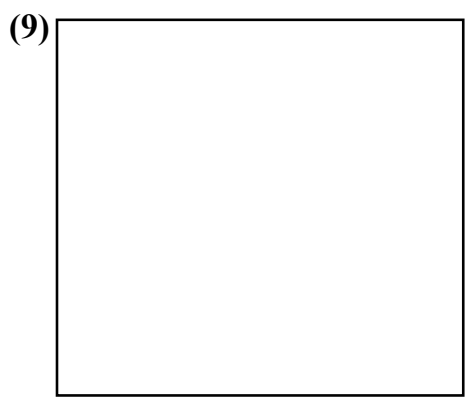

$\mathrm{C}$

(9)
$\mathrm{B}$

$\mathrm{D}$

(9)

Players A and D might be thought of as the row group in the Stag Hunt game, and players $\mathrm{B}$ and $\mathrm{C}$ might be thought of as the column group in the Stag Hunt game. Playing Hare may be thought of as having the pair of players not add a link between them. Playing Stag may be 
thought of as adding a link between the two players. Thus, if A and D add a link between themselves, while B and $\mathrm{C}$ do not, then we end up with the following network and payoffs:

A

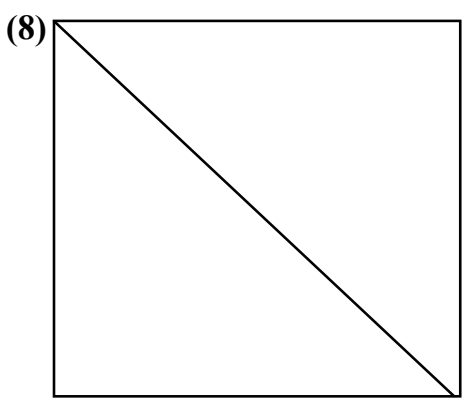

B

(1)
C

(1)
D

(8)

If both groups add a link, then we end up with the following network and payoffs:

A

(8)

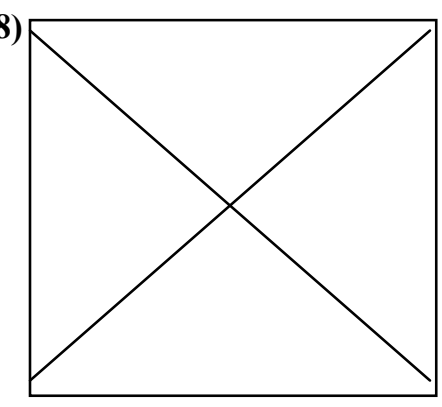

B

(8)

D

(8)

If mutual consent is required to add a link, this is equivalent to having both players have to vote Hare in order to play Hare. If either player in a group can add a link unilaterally, then this corresponds to a single vote being enough to play Hare. Thus the two variations on this 
network game where we vary the consent needed to form a link correspond exactly to the Stag Hunt game played between two groups where the voting rule is varied. ${ }^{4}$

The reasoning that corresponds to that of what is 'focal' when groups play Stag Hunt is as follows. In the game where unilateral consent is needed to form a link, it is 'easier' to form links, and one should expect them to form. If it is more likely that the other pair will add their link, then it is a best response to add a link. In contrast, when it takes mutual consent to form a link, then it can be more difficult for either group to form a link and thus the network where no links are formed becomes more focal.

In terms of predictions from the network-formation literature, we again find that there are multiple equilibria. ${ }^{5}$ For instance, if mutual consent is needed to form a link then we can use the concept of pairwise stability from Jackson and Wolinsky (1996) to develop predictions of which links will form. This asks that no two players wish to add a link, and no single player wishes to delete a link. Here, (subject to the constraint that the initial four links cannot be altered) both the network where neither link is formed and the network where both links are formed are pairwise stable. In the case where single consent is needed, then the game can be viewed as a variation on a link-formation game proposed by Myerson (1990) (see also Bala and Goyal 2000), and Nash equilibrium can be used as a solution concept. Again, there are two (pure-strategy) equilibrium network configurations: one where neither link is added and the other where both links are added. In order to select among the equilibria, we need to employ some coalitional refinement. In the case of mutual consent, strong stability from Jackson and van den Nouweland (2001) will single out the networks that lead to the payoffs of nine, and similarly strong Nash equilibrium will do the same in the case of unilateral link formation.

\footnotetext{
${ }^{4}$ Note that there are other variations of the above network formation game that we can consider. In addition to the two variations that we have already described, we can also reverse the payoff structure. That is, we could have payoffs of 8 when neither link is added, payoffs of 9 when both links are added, and, when exactly one link is added, payoffs of 1 for the group adding a link and payoffs of 8 for the group not forming a link. While these are seemingly different variations on the games, they are again completely strategically equivalent to the others. We ran these variations to check that the framing was not important, and indeed found the results to be indistinguishable across framing, as we detail below.

${ }^{5}$ See Jackson (2003) for a survey of models of network formation.
} 


\section{Experimental Description and Hypotheses}

\subsection{The Experiment}

We conducted a series of experiments in six separate sessions at the University of California at Santa Barbara. There were 16 participants in each session, with average earnings of about $\$ 15$ (including a $\$ 5$ show-up payment) for a one-hour session. The experiments were framed in terms of the formation of links in a network. The complete instructions are presented in Appendix D. Our experiment was programmed using the z-Tree software (Fischbacher 1999).

Participants were sorted randomly into groups, typically with four people in a group. We imposed the initial link network structure of a 'square', where each person was linked to two adjacent parties, with no diagonal links. In three of our sessions, this was the initial network:

A

(9)

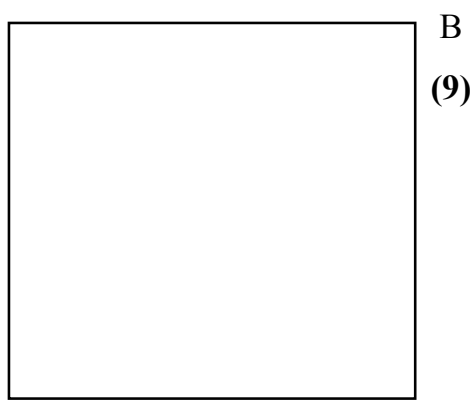

$\mathrm{C}$

(9)
$\mathrm{D}$

$\mathrm{B}$

(9)

(9)

The issue of choice was whether to add a diagonal link, as we described in the introduction. If neither diagonal link was created, each person received nine experimental units. If both diagonal links were created, each person received a payoff of eight. If only one diagonal link was created, the people at the nodes of this link received eight, while the people not connected by a diagonal link received only one.

In the other three sessions, we started with lower default payoffs and also altered the way that payoffs were determined by the links added.

A

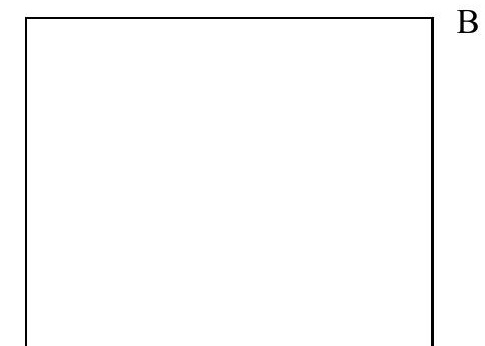


In these sessions, if no diagonal links were added, then each person received a payoff of eight experimental units. If both diagonal links were added, then each person received a payoff of nine. If only one diagonal link was created, the people at the nodes of this link received only one, while the people not connected by a diagonal link received eight.

The contrast between the two sessions is one of framing, as we shall discuss more fully below, as in one case the risk-dominant play is to not add a link while in the other it is to add a link.

There were 60 periods in a session, comprised of four 15-period segments with different decision rules for whether a diagonal link was created. These segments differed with respect to the decision rules for creating a diagonal link. The people in each group were matched with each other for the 15 periods in a segment; after each segment, participants were randomly rematched. Each person was involved exactly once in each of these four different cases:

1) Mutual consent: People are in 4-person groups. Consider the two people diagonally across from each other: A link is added if and only if both of these people wish to add it.

2) Unilateral consent: People are in 4-person groups. Consider the people diagonally across from each other: A link is added if and only if at least one of these people wishes to add it.

3) 2 play for 4: People are in 4-person groups. However, only two of these people will make choices in the game (say players $\mathrm{A}$ and $\mathrm{C}$ in the above diagrams), and they can unilaterally decide whether or not to add their corresponding links. Each one of these people is paired with a silent partner (say players B and D in the above diagrams) who is inactive in the game but whose payoff depends on the play of the game. 
4) 2 play for 2: People are in 2-person groups. In this case each person controls two vertices that are diagonally opposed to each other (so, one player controls vertices A and $\mathrm{D}$ and the other controls $\mathrm{B}$ and $\mathrm{C}$ ). So, one player decides whether one link is added and the other player controls the other link. If a player chooses to add a link, then it is added and he or she receives the payoff that either of his or her vertices would earn.

Participants always knew which case applied before making a decision. Once the decisions for the period were reached, each person learned his or her payoff, the choice of his or her partner (diagonal counterpart), and whether or not the other group (off-diagonals) added a link. Participants also knew that they would learn this information before making subsequent choices.

\subsection{Hypotheses}

As noted above, solution concepts such as pairwise stability and Nash equilibrium do not result in multiple equilibria in our games, and thus leave much open in terms of how play might proceed. We can look to ideas such as risk and payoff dominance to try to select among the equilibria. The notion of risk dominance is consistent with both groups choosing Hare and the notion of payoff dominance is consistent with both players choosing Stag. ${ }^{6}$ We wish to remain agnostic regarding the relative merits of payoff dominance and risk dominance, but note that play should be the same across all treatments if either notion were a consistent underlying force. We find nothing else in conventional theory to guide us. Thus, we formulate four null hypotheses based on the view that behavior will not vary across our experimental games.

Hypothesis 1: (No Effect of Consent) There will be no difference in link formation between the mutual-consent and the unilateral-consent treatments, all else held constant.

Hypothesis 2: (No Effect of Payoff Structure) Link formation will not differ depending on where we start (whether the payoffs are 8 or 9 when no diagonal links are formed), all else held constant.

\footnotetext{
${ }^{6}$ We need to be a bit careful here, as with four players the ideas apply slightly differently than with just two. Nevertheless, the risk-dominant play is still for every player to play Hare, regardless of the voting rule, and payoff dominance has both groups playing Stag, regardless of the voting rule.
} 
Hypothesis 3: (No Framing Effects) Link Formation will not differ in the games starting with 9 's and mutual consent and that starting with 8's and unilateral consent; and similarly play will not differ in the games starting with 8's and mutual consent and those starting with 9's and unilateral consent.

Hypothesis 4: (No Responsibility Effect) There will be no difference in link formation across the 2-for-4 and 2-for-2 treatments, all else held constant.

The above hypotheses are not nested nor are they mutually exclusive, so there is a variety of alternative hypotheses to various sets of the above. Rather than list all of the possible alternatives, let us mention a few.

In the mutual-consent and unilateral-consent treatments, if we adopt the view that links will form if and only if formation requires only one vote, we have an alternative hypothesis:

Hypothesis 1a: There will be more links formed in the unilateral-consent treatments than in the mutual-consent treatments, regardless of the starting payoffs.

This is the critical alternative hypothesis that the method by which groups make decisions affects play.

There are two different views as to how payoffs might affect play, depending on whether one looks to payoff or risk dominance. Strong stability and strong Nash equilibrium give clear predictions in favor of play resulting in payoffs of 9's, while risk dominance gives a clear prediction in favor of play resulting in payoffs of 8's. We thus have two alternative hypotheses.

Hypothesis 2a: There will be more links formed in games starting with 8's than in the games starting with 9's. 
Hypothesis 2b: There will be more links formed in games starting with 9's than in the games starting with 8 's

In terms of an alternative hypothesis to the null that framing has no effect on the play of the game, an alternative is that players will have a tendency to stay with the starting network:

Hypothesis 3a: The predominant play will be not to form links.

Finally, in terms of an alternative hypothesis to the fact that responsibility will not affect play, we suggest the following alternative. If we expect people to be less aggressive if they are responsible for a partner's payoff, then:

Hypothesis 4a: There will be more links formed in the 2-play-for-2 treatment than in the 2-for-4 treatment, when starting at 8 's, and vice versa when starting at 9's.

\section{Analysis of the Experimental Results}

In this section, we first present tables and summary statistics to illustrate our results. We then perform hypothesis tests, analyzing our data from the standpoints of individual behavior patterns and the outcomes by independent 4-person groups, and close with a discussion of changes in play, both over time and as a function of 'bad' outcomes experienced.

\subsection{Summary statistics and charts}

Table 1 shows the group outcomes reached in each of our games: 
Table 1 - Group Outcomes

\begin{tabular}{|c|c|c|c|}
\hline Game & No links & One Link & Both Links \\
\hline Start with 9's \\
\hline Mutual & $161(89.4 \%)$ & $7(3.9 \%)$ & $12(6.7 \%)$ \\
\hline Unilateral & $16(8.9 \%)$ & $9(5.0 \%)$ & $155(86.1 \%)$ \\
\hline 2 play for 4 & $74(41.1 \%)$ & $27(15.0 \%)$ & $79(43.9 \%)$ \\
\hline 2 play for 2 & $190(52.8 \%)$ & $33(9.2 \%)$ & $137(38.0 \%)$ \\
\hline \multicolumn{4}{|l}{} \\
Start with 8's & $16(8.9 \%)$ & $30(16.7 \%)$ \\
\hline Mutual & $134(74.4 \%)$ & $5(2.8 \%)$ & $149(82.8 \%)$ \\
\hline Unilateral & $26(14.4 \%)$ & $21(11.7 \%)$ & $60(33.3 \%)$ \\
\hline 2 play for 4 & $99(55.0 \%)$ & $35(9.7 \%)$ & $217(60.3 \%)$ \\
\hline 2 play for 2 & $108(30.0 \%)$ &
\end{tabular}

Table 1 already gives us a strong look at the hypotheses, and makes it pretty clear what the conclusions will be. While we return to careful statistical tests of the hypotheses with the full data set, let us discuss what these aggregate statistics suggest.

Hypothesis 1, that consent does not matter, will be soundly rejected in favor of the alternative that there are more links formed under unilateral consent - that is, the group decision making rule is an (the) important factor in determining play and it goes in favor of the decision that requires the least votes or consent to achieve. We see this in the contrast between play between mutual and unilateral consent in each of the cases. In particular, under unilateral consent links form in 86.1 and 82.8 percent of the plays, in the starting at 9's and starting at 8 's respectively. This is in stark contrast with the formation of links in only 6.7 and 16.7 percent of the corresponding plays under mutual consent. As we shall see in the formal hypothesis tests below, this is a significant difference.

Hypothesis 2, that the payoff structure does not matter, is not quite as obvious. While link formation seems driven mostly by the consent rule independently of the starting payoffs, there are some slight differences across the starting payoff states. Curiously, however, there is no clear pattern in how the payoff structure matters. With mutual consent, we see slightly less 
link formation when starting with 9's than when starting with 8's, but with unilateral consent this direction is reversed. We revisit this in more detail in the formal tests of the hypotheses below.

Hypothesis 3, that the framing is irrelevant, is also largely consistent with the data. This hypothesis is based on the observation that the mutual consent starting at 9's is strategically equivalent to the unilateral consent starting at 8's, and similarly that the mutual consent starting at 8's is strategically equivalent to the unilateral consent starting at 9's. Indeed, these different treatments exhibit very similar play.

Hypothesis 4, that responsibility does not matter, will be rejected in favor of Hypothesis 4a, that players play more conservatively when responsible another's welfare. We see this as the $(9,9)$ outcome is attained substantially more frequently than the $(8,8)$ outcome in both of the two playing for two games compared to the two playing for four games. The difference is particularly strong when the network starts with the $(9,9)$ payoff.

We also observe that the highly-unattractive 'one link' $(1,8)$ outcome is relatively rare, occurring in only 153 of 1800 cases across all games, or $8.5 \%$ of the time. In the few cases where there is some coordination failure in initial periods, we often see rapid movement to successful coordination.

A different way to look at the data is to consider the individual choices. It is important to look at individual data in order to get a fuller feeling for differences in play. For instance, suppose that players were simply flipping coins in order to decide whether or not to vote to form a link. In that case, more links would be formed under unilateral consent than mutual consent, and not because their play was influenced by the structure of the consent rule, but simply because of the consent rule. In order to test that players' decisions are actually influenced by the consent rule, among other things, we can look at individual level data.

\section{Table 2 - Individual Choices}

\begin{tabular}{|c|c|c|}
\hline Game & No Link & Link \\
\hline \multicolumn{2}{|c|}{ Start with 9's } \\
\hline mutual consent & $512(71.1 \%)$ & $208(28.9 \%)$ \\
\hline unilateral consent & $191(26.5 \%)$ & $529(73.5 \%)$ \\
\hline 2 play for 4 & $175(48.6 \%)$ & $185(51.4 \%)$ \\
\hline 2 play for 2 & $413(57.4 \%)$ & $307(42.6 \%)$ \\
\hline
\end{tabular}




\begin{tabular}{|c|c|c|}
\hline \multicolumn{3}{|c|}{ Start with 8's } \\
\hline mutual consent & $455(63.2 \%)$ & $265(37.8 \%)$ \\
\hline unilateral consent & $185(25.7 \%)$ & $535(74.3 \%)$ \\
\hline 2 play for 4 & $219(60.8 \%)$ & $141(39.2 \%)$ \\
\hline 2 play for 2 & $251(34.9 \%)$ & $469(65.1 \%)$ \\
\hline
\end{tabular}

The patterns seen in Table 1 are also apparent in Table 2, although the differences are not quite as extreme (but are nevertheless highly significant, as we shall see).

We can also consider the choice tendencies of each individual in each game, as well as individual profiles across the three or four games each person played. Table 3 shows how many people in each game either added or didn't add links (or mixed), as well as how common it was for an individual to change his or her strategy over the course of a 15-period segment, and in which direction (from link to don't link, or vice versa): 
Table 3 - Individual Choice Tendencies, by Game

\begin{tabular}{|l|c|c|c|c|c|}
\hline Game & No Link & Mix & Link & Link $\Rightarrow$ No Link & No Link $\Rightarrow$ Link \\
\hline Start with 9's \\
\hline mutual & 34 & 1 & 13 & 4 & 2 \\
\hline unilateral & 6 & 8 & 34 & 2 & 20 \\
\hline 2 play for 4 & 10 & 3 & 11 & 1 & 5 \\
\hline 2 play for 2 & 22 & 0 & 26 & 1 & 7 \\
\hline Start with 8's & \multicolumn{5}{|l}{} \\
\hline mutual & 31 & 4 & 13 & 13 & 1 \\
\hline unilateral & 11 & 0 & 37 & 2 & 5 \\
\hline 2 play for 4 & 15 & 1 & 8 & 6 & 1 \\
\hline 2 play for 2 & 17 & 1 & 30 & 6 & 2 \\
\hline
\end{tabular}

"Mix" means that an individual chose each action at least six times (out of 15)

We see that individual behavior mirrors the patterns observed in Tables 1 and 2. We also see a substantial difference between choices in 2 play for 4 versus 2 play for 2 when starting with 8 's, but only a small difference when starting with 9's.

In the games starting with 9's, there were 42 switches out of 168 possible (25.0\%), while in the games starting with 8's, there were 36 switches out of 168 possible $(21.4 \%)$; in the aggregate, people changed their choice $23.2 \%$ of the time. In the preponderance of these cases (61 of 78, or 78.2\%), we see that this change went from voting for the risky play (trying for 9) to voting for the safe play ( 8 for sure). ${ }^{7}$ While payoff dominance is ultimately trumped by the consent rule, this suggests that many people have some initial attraction to payoff dominance.

Table 4 shows individual profiles across all pairs of games. The complete profiles across all games each person played are shown in Appendix C.

\footnotetext{
${ }^{7}$ Recall that when starting at 9's, a group can guarantee itself a payoff of 8 by adding a link, and when starting at 8 's, this safe payoff is instead guaranteed by not adding a link.
} 
Table 4 - Individual Profiles

\begin{tabular}{|c|c|c|c|c|c|c|c|c|c|}
\hline Game pair & NN & NM & NL & MN & MM & ML & LN & LM & LL \\
\hline Start with 9's \\
\hline mutual \&unilateral & 5 & 6 & 23 & 0 & 1 & 0 & 1 & 1 & 11 \\
\hline 2 for 4 \& 2 for 2 & 9 & 0 & 1 & 2 & 0 & 1 & 3 & 0 & 8 \\
\hline Start with 8's \\
\hline mutual \& unilateral & 10 & 0 & 21 & 0 & 0 & 4 & 1 & 0 & 12 \\
\hline 2 for 4 \& 2 for 2 & 7 & 0 & 8 & 0 & 0 & 1 & 0 & 0 & 8 \\
\hline
\end{tabular}

In this Table, "N" means voted for No Link, "M" means Mix, and "L" means voted for Link

Regarding the mutual and unilateral game-pair, 39 people out of 96 (40.6\%) played about the same in both games. We see that in games starting with 9's, many more people did not add links under mutual consent and added links under unilateral consent than the other way around; the reverse is true in the games starting with 8's. Overall, for the 57 people whose choice behavior differed across the mutual- and unilateral-consent treatments, 54 of the differences (94.7\%) favor being an individual being more aggressive when going Stag (trying for 9) requires only one vote of the two (mapping to mutual consent when starting with 9's or to unilateral consent when starting with 8's).

In the 2 -for- 2 and 2 -for- 4 games, $2 / 3$ of all people ( 32 of 48 ) play about the same whether they are choosing only for themselves or are responsible for another person's payoff. In the games starting with 9's, five people play more aggressively and two people play less aggressively when on their own ( 2 for 2 ). In the games starting with 8 's, nine people play more aggressively and no people play less aggressively when on their own. 


\subsection{Hypothesis tests}

In order to deal with the problem of possibly non-independent multiple observations, we follow a couple of approaches in testing our hypotheses. First, we look at the behavior of each individual in each segment, thereby obtaining one observation for each 15 periods. Second, since there are possible interaction effects, a more conservative test involves average rates for adding links for each group in our sessions. These different approaches also differ in terms of whether they examine individual behavior or equilibrium play.

Hypothesis 1. The data in Tables 1 and 2 show large differences in play, holding starting payoffs constant, according to whether mutual consent or unilateral consent is needed to form a diagonal link. This is depicted in Figure 1 below.

Figure 1 - Link Formation in Four-voter Games

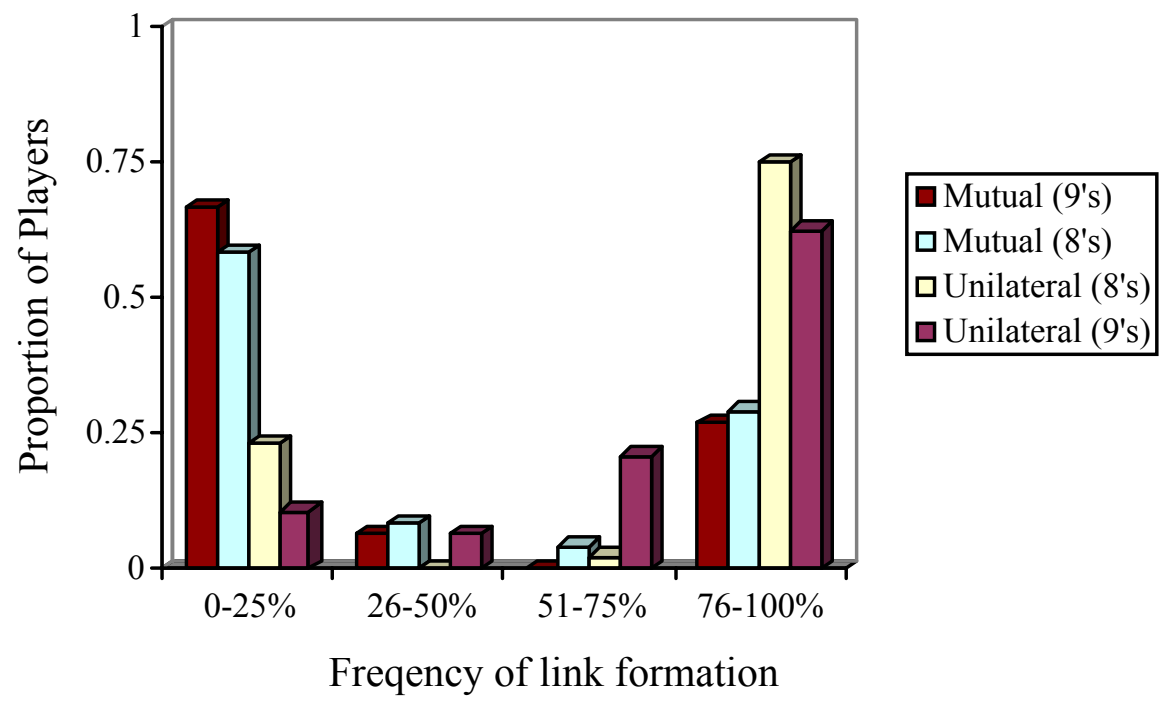

Figure 1 illustrates the central finding of our experiments very starkly: Play is almost entirely dictated by the consent/voting structure, essentially independently of the payoff structure. If we combine the mutual plays and unilateral plays across starting payoffs, we see the difference between consent/voting structures most vividly, as pictured in Figure 2 below. 
Figure 2 - Link Formation in Four-voter Games

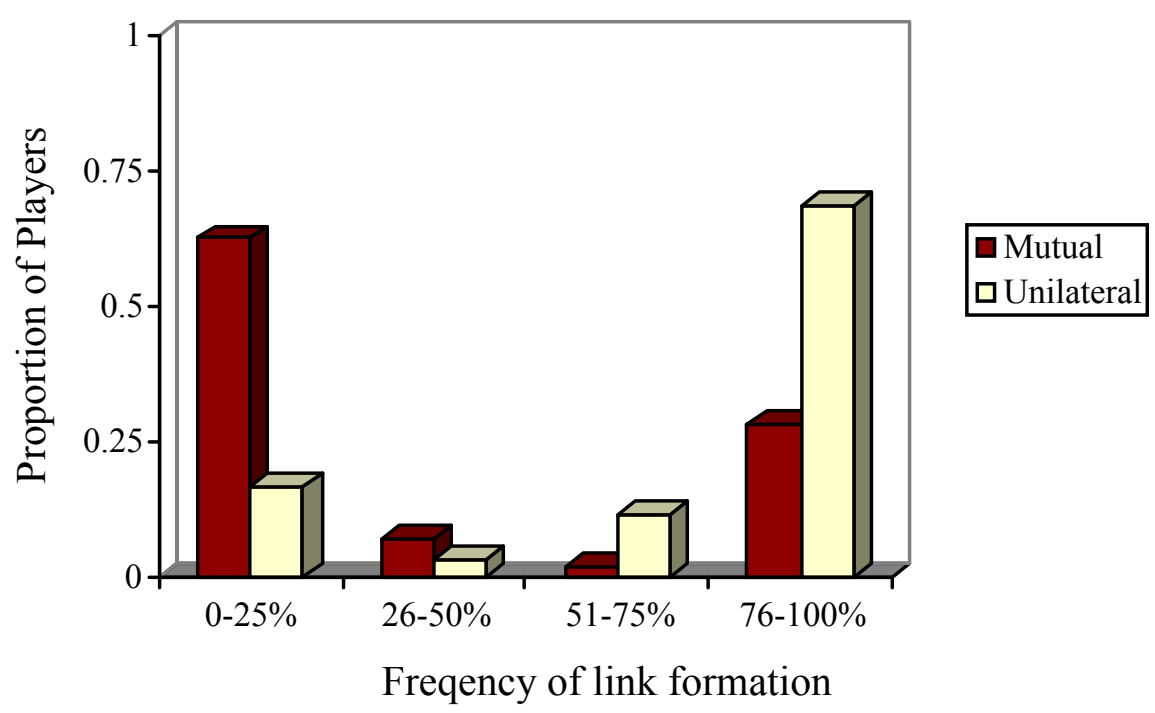

Since each person plays both mutual-consent and unilateral-consent games, we can examine whether these patterns are found within each individual's choices in these games. Table 4 shows that 23 people in the start-with-9 treatment played less 'safe' and only one person played 'safer' in the mutual-consent treatment (only one vote needed to go Stag). Similarly, 21 people in the start-with- 8 treatment played less safe and only one person played safer in the unilateral-consent treatment (only one vote needed to go Stag). If play was unaffected by the consent rule, we should expect to see the number of people playing safer under mutual consent to be about the same as the number of people playing safer under unilateral consent, and clearly this is not the case. Simple binomial tests on these within-individual data find both of these differences are highly significant $(Z=4.49$ and 4.26, respectively, $p<0.00001$ in each case).

A more conservative Wilcoxon-Mann-Whitney rank-sum test (see Siegel and Castellan 1988) using group-level averages confirms significance for these differences $(Z=2.95, p=0.002$ and $\mathrm{Z}=1.91, p=0.028$, respectively, one-tailed tests). ${ }^{8}$ Thus, we can reject Hypothesis 1 in favor of the alternative Hypothesis 1a.

\footnotetext{
${ }^{8}$ The tests compare the total number of links formed by each of the twelve groups under the mutual consent with the corresponding twelve groups under unilateral consent. This gives twenty four groups overall. Each group then has a ranking between 1 and 24 . Under the null hypothesis the sum of the rankings for the twelve groups under mutual consent should be the same as under unilateral consent, subject to random noise. The Z-statistic here is from the difference between the sum of the rankings, mutual minus unilateral, and so the rankings are lower numbers (representing more links) for the unilateral case.
} 
Hypothesis 2. To examine whether or not the payoff structure affects the link formation, we can look back to Figure 1 and make comparisons across starting states. First, let us examine the mutual-consent case, which is drawn out in Figure 3.

Figure 3 - Link Formation under Mutual Consent

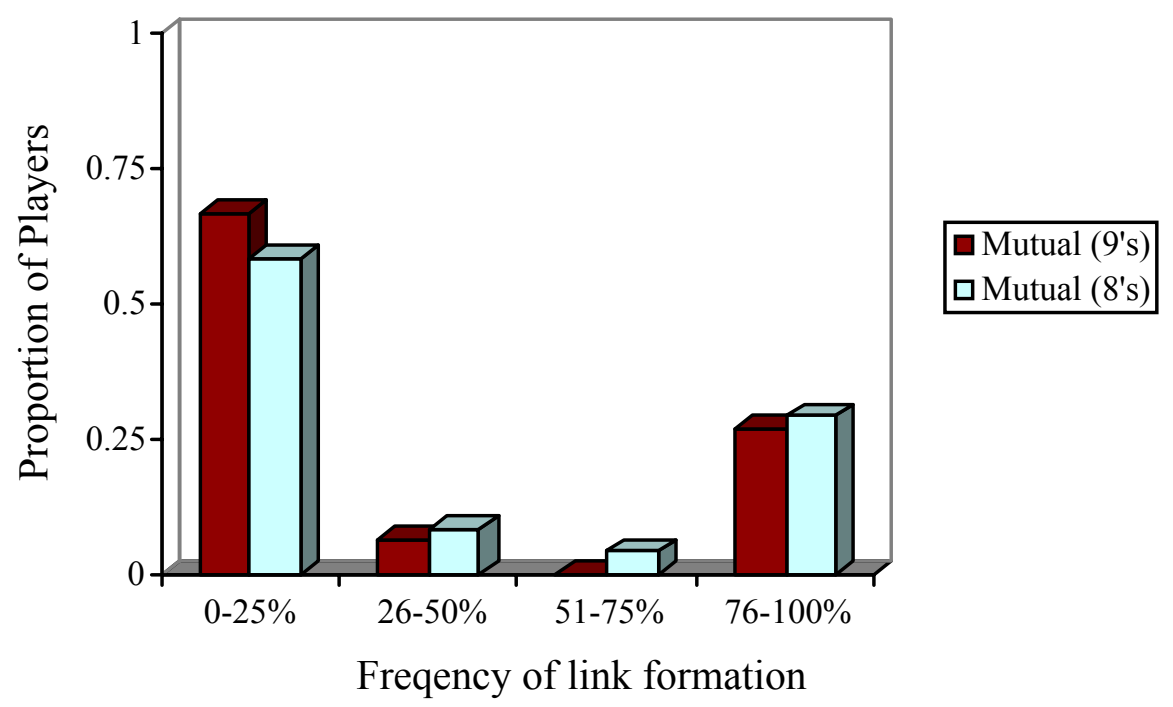

There is a slight tendency (also observed in Tables 1 and 2) for more links to form when starting with 8's than when starting at 9's, which would be consistent with Hypothesis 2a.

To test Hypothesis 2 in the mutual-consent games, we first compare link-addition rates in the mutual-consent game starting with 9's and in the mutual-consent games starting with 8's. Using Wilcoxon rank-sum tests of group-level rates when starting with 9's versus when starting with 8 's, we find $Z=-1.58$ at $p=0.114$, on a two-tailed test, and so fail to reject Hypothesis 2 . A test using individual-level data gives $Z=-1.76$ at $p=0.078$, which is marginally significant depending on the significance level desired. ${ }^{9}$

The analogous plot for the unilateral case is shown in Figure 4.

\footnotetext{
${ }^{9}$ When testing Hypothesis 1 with the individual level data we were able to do a binomial test, as we had data from the same individuals in the two treatments. Here this test cannot be used (since no individual is in both treatments), so we rely instead on the rank-sum test.
} 
Figure 4 - Link Formation under Unilateral Consent

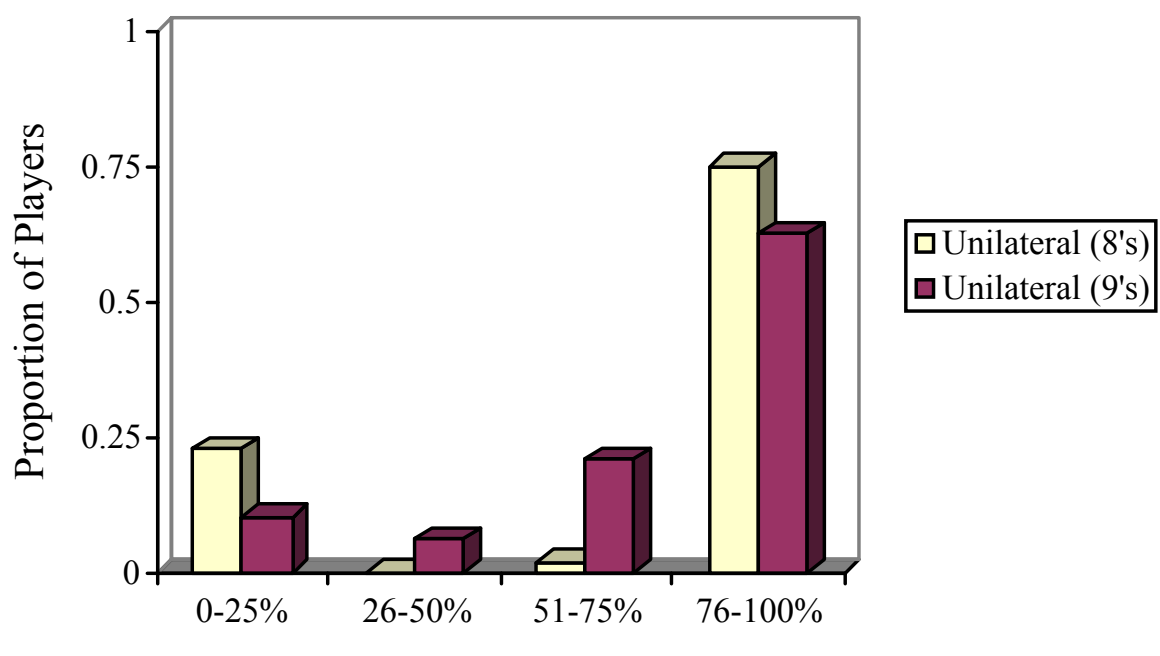

Freqency of link formation

We see a small influence from the starting conditions, although it is a bit ambiguous as we see both extremes in terms of voting when starting with 8's.

The Wilcoxon rank-sum test using group-level link-formation rates gives $Z=-1.27$ at $p=$ 0.204, on a two-tailed test, and so we fail to reject Hypothesis 2 that the payoff structure does not matter. When we examine individual-level data, we obtain $Z=-2.32$ at $p=0.020$ on a twotailed test. Here we reject Hypothesis 2 in favor of Hypothesis 2a, so that more links are formed when the payoff to having both links form is nine. The one-sided tests on the group-level and individual-level data yield $p=0.102$ and $p=0.010$, respectively.

Curiously, the average link-formation rates in Table 1 for the unilateral case show a slight bias towards less link formation when we start at 8's than when we start at 9's, which is in contrast to the conclusion of the hypothesis test above on the individual-level data (and the direction of the statistics for the group-level data ${ }^{10}$ ). A close inspection of the individual-level data shows that when we start at 9's about a fourth of the subjects try to form links between $1 / 3$

\footnotetext{
${ }^{10}$ The group results were dichotomous: 21 of 24 groups formed at least 26 of 30 links, while the either three groups formed two or fewer links. There were two groups with few links in the 8's case, so the average (Table 1) is lower in this case. However, in the 8's case, only one of the 10 groups with a high linkage rate formed fewer than 30 links (29), while in the 9's case, six of the 11 groups in 9's with high linkage rates formed between 26 and 29 links. As the rank-sum test does not include any notion of interval, here the difference between the average and the order statistics is enough to reverse the direction of the bias. If we use a slightly more exotic non-parametric test that does consider interval, such as the permutation test (see Siegel and Castellan 1988), this significant difference disappears.
} 
and $2 / 3$ of the time, while there are no such subjects starting at 8 's (the counterparts in the 8's treatments in terms of rank ordering are attempting to form the links in most all of the periods).

This difference does not show up in the group link-formation data, as the subjects whose choices vary much are almost invariably matched with a partner who has been forming the link during the segment, so that the choice one makes is effectively immaterial. This 'floater' behavior is enough to provide for a significant difference, while no significant difference appears when simply looking at the link-formation rates, and it looks to go in the opposite direction. The sensitivity of the conclusions of the tests of Hypothesis 2 to the level on which it is examined leads us to be cautious, and to come away with the conclusion that there may be a slight bias towards payoff dominance but it is not obvious whether it is significant or not.

Let us now turn to the data for the two-voter games. Figures 5 and 6 picture link formation in these:

Figure 5 - Link Formation in Two-for-Four Games

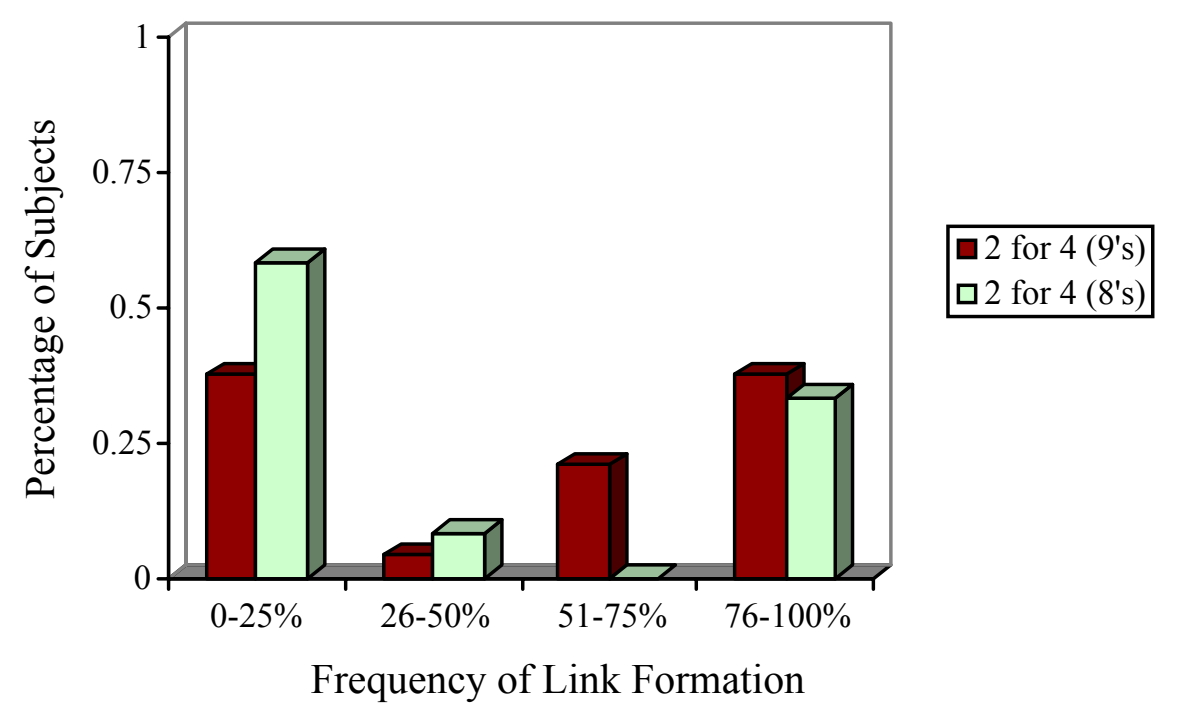


Figure 6 - Link Formation in Two-for-Two Games

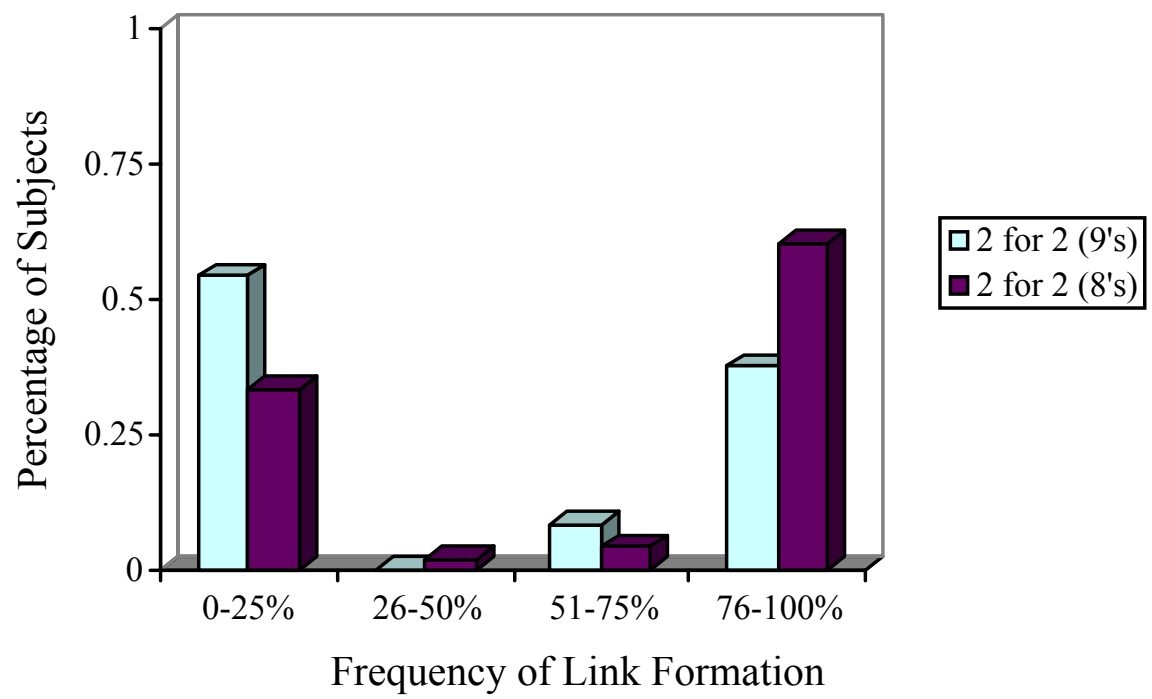

Figures 5 and 6 show an influence of the payoff structure on link formation. In the 2-for2 games players are more likely to add links when links are the risky (Stag) play than when they are the safe (Hare) play. The reverse is true in the 2-for-4 games.

When we test Hypothesis 2 using Wilcoxon rank-sum tests on the 2-for-2 games, both individual-level and group-level rates of link formation show large differences going against Hypothesis 2 and in favor of the alternative Hypothesis $2 \mathrm{a}(Z=-3.12$ and $Z=-2.96$, respectively) and even two-tailed tests of Hypothesis 2 reject it at $p=0.002$ and $p=0.003$. The data from the 2-for-4 games cannot reject Hypothesis 2 using the Wilcoxon rank-sum test with either grouplevel or individual data $(Z=0.26$ and $Z=0.27$, respectively), although they go slightly in the direction of Hypothesis 2b. The contrast between 2-for-2 games and 2-for-4 games is actually consistent with Hypothesis $4 \mathrm{a}$, which states that players tend to behave more safely when responsible for another's payoff.

Hypothesis 3. As mentioned above, the rate of risky play is quite similar across 'strategically-equivalent' games. This is clear in the following figures: 
Figure 7 - Stag (Risky) play when it requires one vote

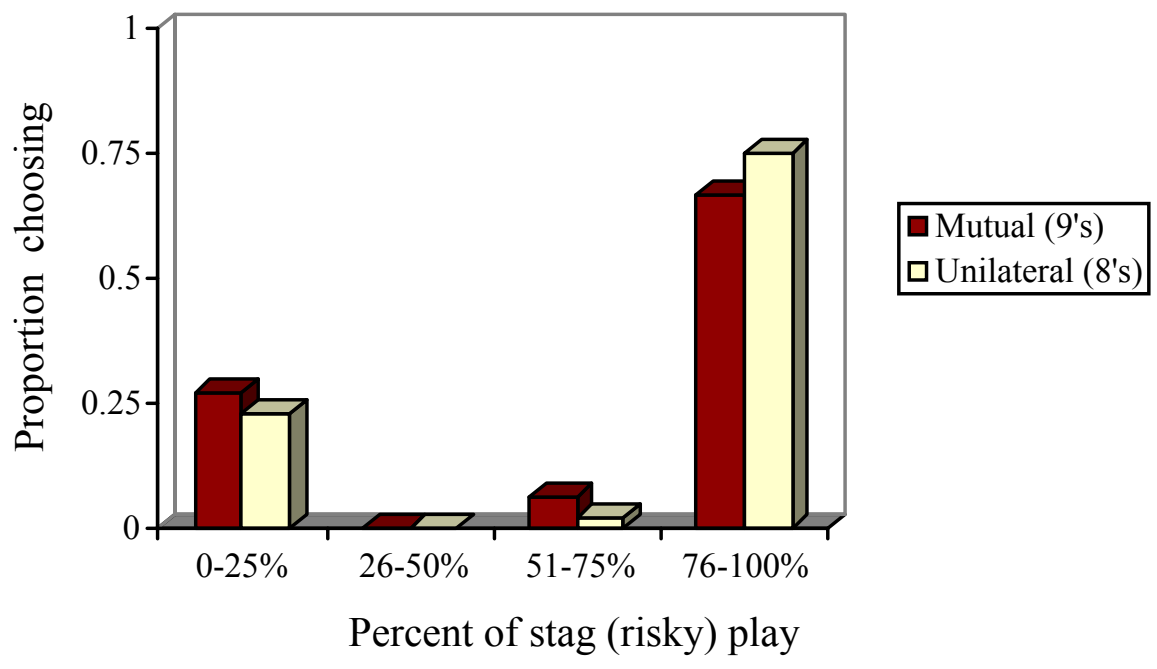

Figure 8 - Stag (Risky) Play when it requires two votes

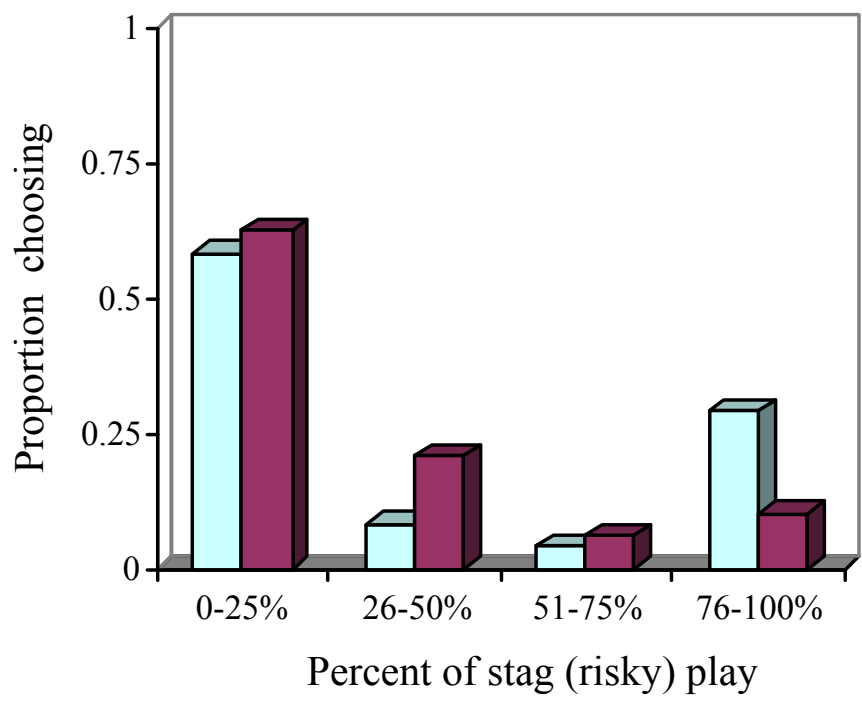

$\square$ Mutual (8's)

$\square$ Unilateral (9's)

The Wilcoxon rank-sum test finds no significant difference in individual rates of risky play across either the mutual-consent game starting with 9's and the unilateral-consent game starting with 8's $(Z=0.40, p=0.689$, two-tailed test) or across the mutual-consent game starting with 8's and the unilateral-consent game starting with 9's ( $Z=0.48, p=0.631$, two-tailed test). Superficially the games might appear quite different, as they have a different consent structure 
and payoff structure. However, the play is unaffected by the framing and matches across strategic equivalents and we do not reject Hypothesis 3, while play starkly contrasts across the games that are not strategically equivalent.

All in all, our data support the notion that players play the strategies corresponding to the 'easier' outcome - links form when consent is unilateral and do not form when formation requires mutual consent; and that this is independent of the payoff structure and the framing of the game. In terms of the Stag Hunt game, this corresponds to playing the strategy that only requires one vote to be played.

Hypothesis 4. We refer to Table 4 for individual choice patterns. It is also helpful to look at the data graphically. We can break these down by different starting conditions. Figure 9 considers the frequency of risky play when the starting network is the 'risky' one (starting with 9's):

Figure 9 - Risky (Stag) Play in Two-voter Games (Starting with 9's)

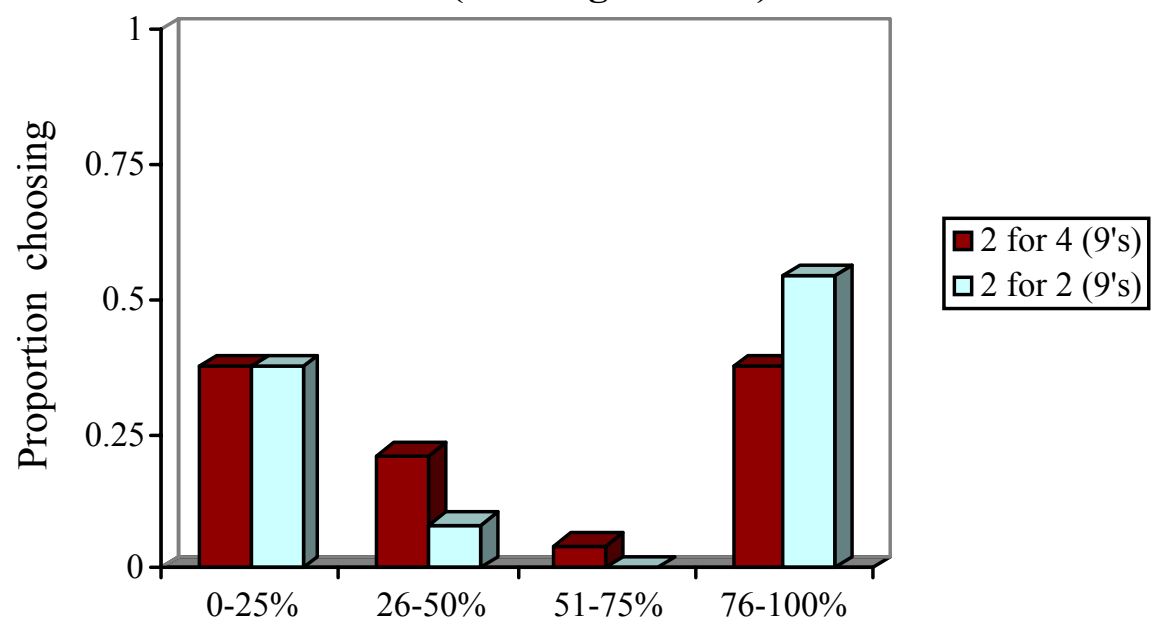

Frequency of risky play

We see slightly more risky play in the 2 -for- 2 games. Figure 10 depicts the differences when starting at 8 's, where the difference is more pronounced. 
Figure 10 - Risky (Stag) Play in Two-voter Games

(Starting with 8's)

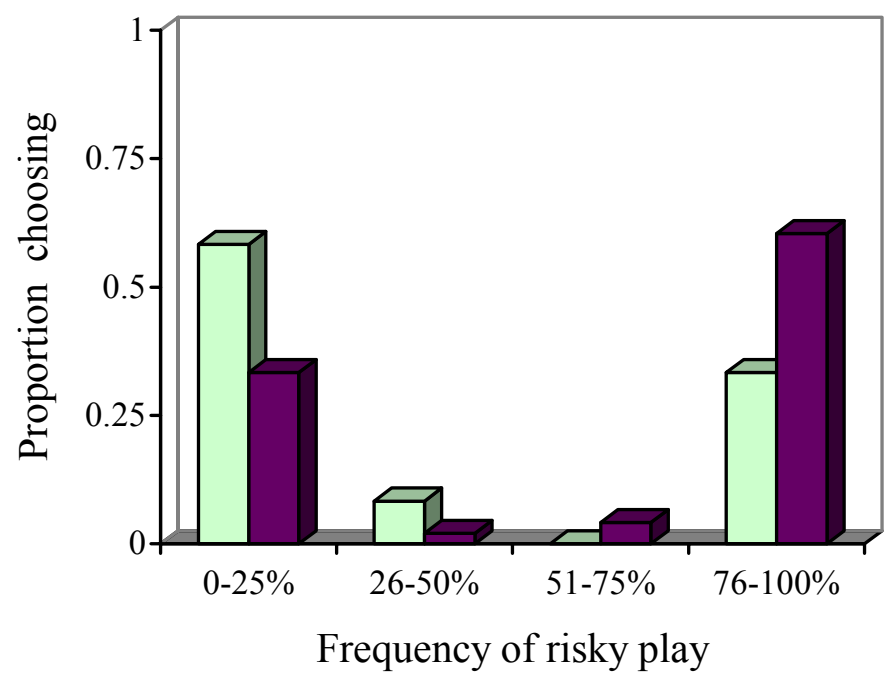

$\square 2$ for 4 (8's)

$\square 2$ for $2(8 ' s)$

If we aggregate across strategically-equivalent games, to compare the 2-for-4 games versus the 2-for-2 games overall, we end up with Figure 11:

Figure 11 - Risky (Stag) Play in Two-voter Games

(Aggregated)

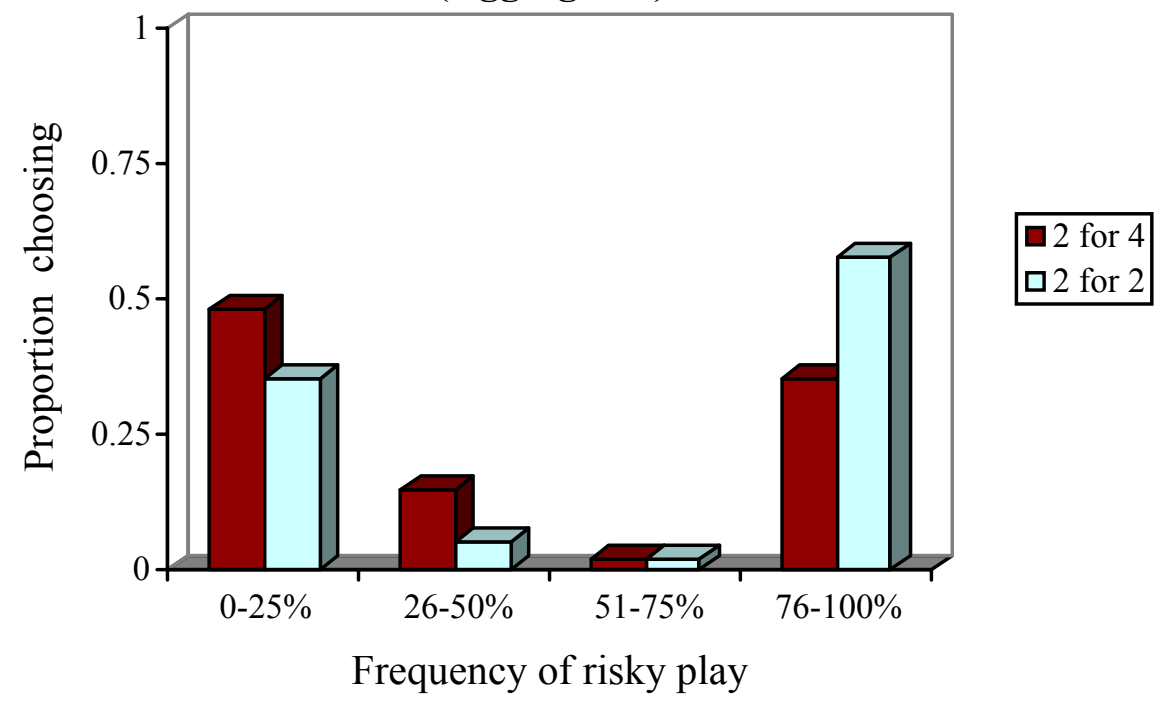

We have only half the number of paired individual comparisons for comparisons between the 2-for-4 and 2-for- 2 games, as half of the participants did not make choices in the 2-for-4 
games. Given the parallels between the starting states noted above, we pool comparisons (2-for4's across starting states and 2-for-2's across starting states) and find that 14 people made the risky play more frequently when on their own than when responsible for a silent partner's payoff and two people played stage less frequently when on their own. The binary test gives $Z=3.00$, significant at $p=0.001$. When we use the more conservative test with group averages, we again see that aggressive play is more likely in the pooled 2-for- 2 treatments than in the pooled 2-for-4 treatments, although in this case the difference is only marginally significant $(Z=1.34, p=$ 0.090, one-tailed Wilcoxon rank-sum test). Thus, while most people play the same in both cases, there seems to be a tendency among a substantial minority of the population to take fewer chances when responsible for a non-enfranchised person's welfare. We reject Hypothesis 4 in favor of Hypothesis $4 \mathrm{a}$.

\subsection{Changes over time and determinants}

Does the tendency to play the risky strategy (Stag) change appreciably over time? If so, can we isolate any determinants of this change? Table 5 shows the average rate of risky play in the first five periods of the segment, the middle five periods of the segment, and the last five periods of the segment for each of our eight games: 
Table 5 - Rates of Risky Play over Time, by Game

Rate of Risky Play in:

\begin{tabular}{|c|c|c|c|}
\hline Game & $\begin{array}{c}\text { First five } \\
\text { periods }\end{array}$ & $\begin{array}{c}\text { Middle five } \\
\text { periods }\end{array}$ & $\begin{array}{c}\text { Last five } \\
\text { periods }\end{array}$ \\
\hline \multicolumn{4}{|l|}{} \\
\hline Start with 9's \\
\hline mutual & .6875 & .7125 & 7333 \\
\hline unilateral & 3958 & .2083 & .1917 \\
\hline 2 play for 4 & .5250 & .4667 & .4667 \\
\hline 2 play for 2 & .6333 & .5458 & .5417 \\
\hline Start with 8's & & & .3250 \\
\hline mutual & 4392 & .3500 & .7500 \\
\hline unilateral & .7375 & .7417 & .3417 \\
\hline 2 play for 4 & .4583 & .3750 & .6292 \\
\hline 2 play for 2 & .6875 & .6375 & \\
\hline
\end{tabular}

There is generally not much change over time, with a general slight trend toward less risky play. However, we see a substantial drop in risky play from the first five periods to the middle five periods for both of the 2-play-for-4 games, as well as for the unilateral treatment and the 2-play-for-2 game when starting with 9's and the mutual treatment when starting with 8's.

Why do people switch their behavior over the course of a segment? One would naturally suspect that this decision is correlated with having previously experienced bad (payoff $=1$ ) outcomes during the segment. In fact, random-effects probit regressions strongly confirm this conjecture: 
Table 6 - Determinants for Risky Play When Four People Make Decisions

Dependent Variable

\begin{tabular}{|c|c|c|}
\hline Independent variables & Vote for Risky Play & Vote for Risky Play \\
& $(1)$ & $(2)$ \\
\hline Two votes to go Stag & $-1.732^{* * *}$ & $-1.755^{* * *}$ \\
One bad outcome & {$[0.078]$} & {$[0.079]$} \\
& $-1.158^{* * *}$ & $-1.194^{* * *}$ \\
Two bad outcomes & {$[0.151]$} & {$[0.150]$} \\
& $-2.635^{* * *}$ & $-2.754 * * *$ \\
Three or more bad outcomes & {$[0.245]$} & {$[0.244]$} \\
& - & $-0.815 * * *$ \\
Constant & - & {$[0.213]$} \\
& $0.468^{* * *}$ & $0.503 * * *$ \\
\hline \# Observations & {$[0.101]$} & {$[0.116]$} \\
\hline Log-likelihood & 2880 & 2880 \\
\hline
\end{tabular}

Standard errors are in brackets. $* * *$ indicates significance at $0.1 \%$

In these games, people are much more likely to play safe when it takes unanimity for the group to make the risky link choice. A player who has experienced one bad outcome is substantially less likely to vote for the risky play. The effect of a second bad outcome is much stronger, as the coefficient is even larger than that for the treatment effect. However, a person who persists in voting for the risky play after two bad outcomes doesn't seem to care much about bad outcomes, as we see in specification (2) that the coefficient for the effect of three or more bad outcomes is actually smaller than the coefficient for having had only one bad outcome.

\section{A Foundation for the Selection of Equilibrium}

Our experiments exhibit patterns and regularities in the way that groups play these games. In particular, while the games in question have multiple strict Nash equilibria, there is a tendency to focus in on specific ones: those 'favored' by the voting rule, as evidenced by the 
sound rejection of Hypothesis 1. This is exhibited even when the payoffs are altered, and so the selection cannot be attributed to equilibrium refinements such as risk dominance or payoff dominance. None of the other standard equilibrium refinements, such as trembling hand perfection or stochastic stability, predict the selection that the participants are consistently making either. ${ }^{11}$ Nevertheless, there is a clear logic behind the behavior of the subjects, which suggests that there should be an equilibrium concept to capture it. In this section, we use the intuition and observed play in these experiments to develop a new equilibrium concept. It builds on tools from perfection and stochastic stability, but in a way to capture the logic that seems to be underlying the behavior in our experiments.

We begin by explaining the underlying ideas; to do so we consider an abstract two-bytwo game that has two pure-strategy equilibria. For this discussion, consider a coordination game where, as will become clear, the symmetry of payoffs is irrelevant to the general development of the solution concept.

Player 2 Role

(Group 2)

A B

Player 1 Role A a, a c, d

(Group 1)

B d, c b, b

Let $\mathrm{a}>\mathrm{d}$ and $\mathrm{b}>\mathrm{c}$, so that the game has two pure-strategy equilibria, A,A and B,B. Assume that $(a-d)>(b-c)$, so that $A, A$ is the risk-dominant equilibrium in the sense of Harsanyi

\footnotetext{
${ }^{11}$ Even the application of the theory of global games (see Carlsson and van Damme 1993) does not work here. With the right specifications of uncertainty, this sort of game can be analyzed using the techniques of Morris, Frankel and Pauzner (2001). However, depending on the structure of uncertainty that is introduced, it seems that the selection is made either in favor of the risk dominant, or in favor of the payoff dominant payoffs (viewed as a two-player game); and that the selection is not being made relative to the voting rule.
} 
and Selten (1988). ${ }^{12}$ The game in our experiments fits into this setting. Let each player role be filled by some group of at least two individuals. Describe a group's method of selecting a strategy by a quota rule $q$, where $q$ in $\{1, \ldots, \mathrm{n}\}$ denotes the minimum number of votes for strategy A needed before A is played. Thus, if $q$ or more members of the group vote to play A, then A is played, while if fewer than $q$ members of the group vote to play A, then B is played.

Let a state be a list of each individual's play - so it is a vector of length $2 n$ where entries are either A or B. Given a state, each player has a best response. That is, considering a conjecture that other players will play as described in a state, each player has a best response. A pure-strategy Nash equilibrium is then just a state where the state's prescription of each player's vote is a best response given the anticipation that the state correctly describes the voting behavior of the players.

There are many pure-strategy equilibria of such a game. Any profile of votes where both groups pick A is an equilibrium; any profile of votes where both groups pick B is an equilibrium; and any profile of votes where one group picks A, the other group picks B, and no voter is pivotal, is also an equilibrium. In fact, all of these states are undominated Nash equilibria. ${ }^{13}$ Moreover, all voting $\mathrm{A}$ is a trembling-hand-perfect equilibrium, as is all voting $\mathrm{B}$.

The behavior in our experiments, however, picks out the equilibrium that is 'favored' by the voting rule. That is, if $q$ is less than or equal to $n / 2$, then all voting $\mathrm{A}$ is observed, while if $q$ is greater than $n / 2$ then all players voting $\mathrm{B}$ is observed. ${ }^{14}$ On one level we might think of this as a 'focal' effect, in that the bias in the voting rule focuses attention on one of the equilibria. Yet, there are many different things that might be used to 'focus' the attention of the players. For instance, why isn't it that the highest payoff equilibrium becomes the 'focal' one? The challenge for an equilibrium concept is to capture the focal nature of the voting rule, and to do it in a robust way that is not ad hoc to the games in question.

Let us go through some heuristic reasoning that suggests an equilibrium concept. Consider a player forecasting the play of the others. If the player starts agnostically, and simply

\footnotetext{
${ }^{12}$ This equilibrium has the property that each player is choosing a strategy that is also a best response to the other player mixing 50/50. Thus, A is the strategy that is a best response to the largest set of beliefs over possible plays of the opponent, and so the risk-dominant equilibrium is the pure-strategy equilibrium with a larger basin of attraction than the other pure-strategy equilibrium. Specifically, playing A is a player's best response if the probability that his opponent plays $\mathrm{A}$ is greater than or equal to $(\mathrm{b}-\mathrm{c}) /(\mathrm{a}-\mathrm{d}+\mathrm{b}-\mathrm{c})<1 / 2$. Thus if $\mathrm{a}=3, \mathrm{~b}=1$, and $\mathrm{c}=\mathrm{d}=0$, then playing $\mathrm{A}$ is a best response if the belief is that the probability is $1 / 4$ or more that a player's opponent plays $\mathrm{A}$.

${ }^{13}$ Some of these can be ruled out by 'trembling' arguments, but we still end up with no real selection in outcomes.
} 
assumes random voting by the players in the other group, then the forecast would be that the other players would end up playing the strategy favored by the voting rule. While this is rather simplistic reasoning that does not account for payoffs, we can take it further to consider further levels of reasoning. Imagine now that a player starts with any forecast of other players' behavior based on the payoffs and the structure of the game. The player can still think about how sensitive this forecast is to the play of the others. For instance, in our games where $n=2$ and the quota is 1 to play $\mathrm{A}$, then the player realizes that if either of the players in the other group plays A then it is in her interest to play A. Moreover, it is enough for her to believe that one of the other players reasons this way to induce one of the other players to play A. Or, it is enough for her to believe that one of the other players might believe that she is going through this logic, etc. This suggests looking at basins of attraction of equilibria to try to capture some of this reasoning. The primary notion that builds on basins of attraction is stochastic stability. ${ }^{15}$ Can we bring stochastic stability off the shelf and apply it here? There are two problems. First, stochastic stability is generally used in evolutionary analyses where agents either play games against randomly-selected opponents repeatedly over time, or else are playing strategies simultaneously against many other players. This is easily overcome, as it is merely a matter of interpretation. ${ }^{16}$ That is, the machinery of stochastic stability still captures ideas underlying basins of attraction and robustness of equilibria even when the game is only played once by a given set of players. The second problem is the more crippling one: stochastic stability does not make much of a selection here. Let us discuss this in the context of the game we used in our experiments, where the voting rule is that it takes one vote to go Stag and two votes to go Hare.

Consider movement among states, and start at a state where all players vote to go Stag. In this case, every player has two best responses: either voting Stag or Hare. So, completely consistently with best-response behavior, we can move to a state where one player in one of the groups votes Hare. From there we can move to a state where one player in each group votes Hare. Now it takes a single 'tremble' or 'error' on the part of some player to switch to a state where two players in one of the groups vote Hare while only one player in the other group votes Hare. Once in this state, it is now a best response for the only remaining player who is voting

\footnotetext{
${ }^{14}$ We have only examined particular parameter values for the game and number of players, so this is clearly an extrapolation of what is occurring in these games.

${ }^{15}$ See Foster and Young (1990), Kandori, Mailath and Rob (1993), and Young (1993) and the literature that follows.
} 
Stag to switch to voting Hare. ${ }^{17}$ So, it took only one tremble or error in this whole sequence to get us to move from the equilibrium where all players vote Stag to one where all players vote Hare. It is easy to check that the same is true in reverse. This means that both equilibria are stochastically stable: both will be in the long-run steady-state distribution of a carefully-defined Markov process where trembles are introduced.

What's missing from this reasoning? Suppose we start from a state where all players vote Stag, and we also know that there is some unpredictability (real or imaginary) in players' votes so that they might vote Hare with a small probability. That is, players are fully aware of the noise in the process and take that into account when making their decisions. Now, choosing Hare makes it more likely that my group will cross the threshold and fail to coordinate, as I realize that one tremble by my partner will lead to coordination failure (whereas, by playing Stag it will require two errors for coordination failure). Straightforward calculations show that now Hare is the unique best response. ${ }^{18}$ Now, it takes at least two errors or trembles to get from voting Stag to voting Hare, and only one to go back. Using this reasoning, players being somewhat unsure of the other players' play leads to a unique selection from the game. The key difference between this and the usual definition of stochastic stability is that players are not bestresponding to the state, but rather to the state with the understanding of the full process including errors. This seems like a subtle difference, but it is a critical one not only in changing the predictions of the solution concept, but also in capturing the reasoning that might underlie what we observe in the experiments.

Now let us move to a formal definition of the solution concept. It uses ideas from stochastic stability to capture basins of attraction and robustness, and yet has players bestresponding to the actual process to capture the importance of their beliefs (rather than viewing players as random mutations in an evolutionary soup).

We define robust-belief equilibrium for an arbitrary game as follows:

\footnotetext{
${ }^{16}$ See Jackson and Watts (2002) for a model of stochastic stability in network formation and some discussion of possible interpretations.

${ }^{17}$ We could also have one of the players in the other group switch back to Stag - but that is irrelevant to this argument.

${ }^{18}$ There is a probability of $(1-\varepsilon)^{3}$ that all others vote stag, a probability on the order of $\varepsilon$ that one other player votes Hare, and a probability on the order of $\varepsilon^{2}$ or less that two or more other players vote Hare. This means voting Stag leads to a probability on the order of $\varepsilon^{2}$ for coordination failure, while voting Hare leads to a probability on the order of $\varepsilon$ for coordination failure. For small $\varepsilon$ the expected payoff is strictly higher from voting Stag.
} 
Consider an arbitrary finite game $\mathrm{G}=(\mathrm{N}, \mathrm{S}, \mathrm{u})$, where (with an abuse of notation $\mathrm{N}=\{1, \ldots, \mathrm{N}\}$ is a set of players, $\mathrm{S}=\mathrm{S}_{1} \times \ldots \times \mathrm{S}_{\mathrm{N}}$ is the finite set of pure strategies available to players, and $\mathrm{u}=\left(\mathrm{u}_{1}, \ldots \mathrm{u}_{\mathrm{N}}\right)$ is the profile of von Neumann-Morgenstern utility functions, $\mathrm{u}_{\mathrm{i}}: \mathrm{S}_{\mathrm{i}}$ $\rightarrow$ R. Given a game $G$ and an $\varepsilon>0$, let $G(\varepsilon)$ be the following variation on the game. Each player trembles from their prescribed strategy with probability $\varepsilon, 1>\varepsilon>0$. In particular, if a player chooses a given strategy then with probability $1-\varepsilon$ the player's strategy is played and with probability $\varepsilon$ the player's strategy is chosen to be any action with equal probability. ${ }^{19}$

Given a game variant $G(\varepsilon)$, define a Markov process as follows. A state is a profile of strategies $\mathrm{s}$ in S. For each state, let players pick a best response to that state in the game G(E) that is forecasting that the other players will try to play according to $\mathrm{s}$, but may tremble. This defines a function $\beta$ from $S$ to $S$. There may be multiple best responses, so there are may be multiple functions $\beta$. For small enough $\varepsilon$, some $\beta$ 's remain a best-response selection for all smaller $\varepsilon$. Let the set of such $\beta$ 's that remain best-response selections for small $\varepsilon$ 's be denoted $B(\mathrm{G})$. Any selection of best responses $\beta$ in $B(\mathrm{G})$, together with the tremble probabilities defines a transition matrix across states. We end up with a Markov process $M(\mathrm{G}, \varepsilon, \beta)$ that is irreducible and aperiodic. Thus, $M(\mathrm{G}, \varepsilon, \beta)$ has a unique steady-state distribution.

Given a game $\mathrm{G}=(\mathrm{N}, \mathrm{S}, \mathrm{u})$, a robust-belief state is any state that has positive probability under the limit of the steady-state distribution of $M(\mathrm{G}, \varepsilon, \beta)$ as $\varepsilon$ goes to 0 for some best-response selection $\beta$ in $B(\mathrm{G})$. If $\mathrm{s}$ is a state that is both a Nash equilibrium and a robust-belief state, then it is said to be a robust-belief equilibrium. ${ }^{20}$

Given a game $\mathrm{G}=(\mathrm{N}, \mathrm{S}, \mathrm{u})$, a strongly robust-belief state is any state that has positive probability under the limit of the steady-state distribution of $M(\mathrm{G}, \varepsilon, \beta)$ as $\varepsilon$ goes to 0 for all best response selections $\beta$ in $B(\mathrm{G})$. If $\mathrm{s}$ is a state that is both a Nash equilibrium and a strongly robust-belief state, then it is said to be a strongly robust-belief equilibrium.

Let us now return to the coordination game mentioned above.

\footnotetext{
${ }^{19}$ One can easily modify this to allow for different $\varepsilon$ 's for different players, and to have non-uniform probabilities on the actions that are chosen in a 'tremble'.

${ }^{20}$ In some games (such as matching pennies) the process will cycle among a set of states, none of which are equilibria. In that case, these states might be thought of as robust and 'likely' states, but are not equilibria in and of themselves. This means that while robust-belief states will always exist, robust-belief equilibria might not, as this is a pure-strategy concept.
} 
Theorem 1 There is a unique robust-belief state in the group-play coordination game where both groups vote using the quota $q$ : it is all players voting $A$ if $q$ is less than or equal to $n / 2$, and all players voting $B$ otherwise. Moreover this state is a strongly robust-belief equilibrium.

An important observation about Theorem 1 is that the conclusions are completely determined by the voting rule and independent of the levels of the payoffs (a,b,c,d - subject to the inequalities defining the coordination structure), Indeed this is consistent with what we observe in the experiments!

The formal proof appears in the appendix, but we present a brief outline here. For small enough $\varepsilon$, any best-response correspondence is such that if the other group is electing to play A, then any player should vote to play A, and similarly for B. This comes from the fact that agents are anticipating that there might be trembles by other players and acting accordingly. This means that from any state where both groups are electing A, then all voters will best-respond by voting $\mathrm{A}$, and similarly for $\mathrm{B}$. There is also leads to another situation where one group is electing A and the other is electing B, and this will lead all voters in the first group to vote for B and all voters in the second group to vote for A. This provides for two states where the groups fail to coordinate and keep 'flip-flopping' and continue to fail to coordinate. Any state thus leads naturally through best responses to one of these situations.

In order to determine what the robust-belief states are, we need to see how hard it is to move from one of these three classes of situations to another. The key to the theorem is that it takes at least $\mathrm{n}-\mathrm{q}+1$ 'trembles' in order to leave the situation where all voters are voting $\mathrm{A}, \mathrm{q}$ trembles to leave a situation where all voters are voting $\mathrm{B}$, and the minimum of these two numbers to leave the 'flip-flopping states'. The state that is hardest to leave in this setting ends up being the one which gets all of the probability in the steady state distribution when $\varepsilon$ becomes small. This is entirely determined by which is the larger of $\mathrm{q}$ and $\mathrm{n}-\mathrm{q}+1$, and must be either the state where all voters vote for A or the state where all voters vote for B.

\section{Conclusion}


We have explored behavior in a Stag Hunt that can be interpreted as either endogenous link-formation in networks or as a study of how the voting rule that a group uses for decision making impacts the play of a game. We find a stark contrast between how groups and individuals play our games; in the group games, the decision rule is the primary determinant of play, independently of the payoff structure - when hunting Stag requires unanimous consent (two votes), few people elect to hunt Stag; however, when it only takes one vote to hunt Stag, few people elect to hunt Hare. Thus, even when group members all have the same payoff structure, we have different predictions for how groups play games compared to how individuals play games. To encapsulate our findings about group decision-making in a theoretical framework, we develop a new solution concept, robust-belief equilibrium.

We also find that the behavior of about one-third of the population is sensitive to the issue of being responsible for another person's welfare. In about $90 \%$ of these cases, the decider takes on less risk when he or she is the agent for another party than when acting only for him or herself.

As our experiments were limited to a specific game, it would be interesting to see to what extent group decision making processes are critical determinants of play in other sorts of games, and more generally how this varies with the structure of the game. It would also be interesting to further investigate the behavior of robust-belief equilibria.

Let us close with a final observation regarding our experimental results. The equilibrium notions here are myopic ones. There are also notions of farsighted network formation, such as those of Page, Wooders and Kamat (2001) and Dutta, Ghosal and Ray (2003). In the context of the networks we have examined, they would select equilibria where the efficient network is formed (all 9's). ${ }^{21}$ This is not the behavior observed here, although perhaps because our setting is sufficiently different in structure so as not to favor such forward-looking behavior. ${ }^{22}$

\footnotetext{
${ }^{21}$ The Dutta, Ghosal and Ray (2003) definition is in the context of an infinite game of network formation, and would require a sufficiently high discount factor. Their analysis would not have any specific prediction in the context of our game as it is outside of their setting. Nevertheless, the reasoning that they are attempting to capture is consistent with some of the attempts of players in the game to play Stag, with the hope that others will see this and follow suit. The analysis of Page, Wooders and Kamat (2001) is independent of a particular protocol, as it builds on Chwe's (1994) largest consistent set.

${ }^{22}$ See Pantz, K. and A. Ziegelmeyer (2003) for a more detailed study of myopic versus farsighted behavior in network formation.
} 


\section{Appendix A}

\section{Proof of Theorem 1:}

A theorem from Young (1993) is instrumental in the proof of Proposition 1. Before stating Young's theorem, the following definitions from Young (1993) are needed.

Consider a stationary Markov process on a finite state space $\mathrm{X}$ with transition matrix $\mathrm{P}$.

A set of mutations of $\mathrm{P}$ is a range $(0, \mathrm{a}]$ and a stationary Markov process on $\mathrm{X}$ with transition matrix $\mathrm{P}(\varepsilon)$ for each $\varepsilon$ in $(0, \mathrm{a}]$, such that (i) $\mathrm{P}(\varepsilon)$ is aperiodic and irreducible for each $\varepsilon$ in $(0, \mathrm{a}]$, (ii) $\mathrm{P}(\varepsilon) \rightarrow \mathrm{P}$, and (iii) $\mathrm{P}(\varepsilon)_{\mathrm{xy}}>0$ implies that there exists $\mathrm{r} \geq 0$ such that $0<\lim _{\varepsilon-\mathrm{r}} \mathrm{P}(\varepsilon)_{\mathrm{xy}}<\infty$.

The number $\mathrm{r}$ in (iii) above is the resistance of the transition from state $\mathrm{x}$ to $\mathrm{y}$. There is a path from $\mathrm{x}$ to $\mathrm{z}$ of zero resistance if there is a sequence of states starting with $\mathrm{x}$ and ending with $\mathrm{z}$ such that the transition from each state to the next state in the sequence is of zero resistance. Note that from (ii) and (iii), this implies that if there is a path from $\mathrm{x}$ to $\mathrm{z}$ of zero resistance, then the $\mathrm{n}$-th order transition probability associated with $\mathrm{P}$ of $\mathrm{x}$ to $\mathrm{z}$ is positive for some $\mathrm{n}$.

The recurrent communication classes of $\mathrm{P}$, denoted $\mathrm{X}_{1}, \ldots, \mathrm{X}_{\mathrm{J}}$, are disjoint subsets of states such that (i) from each state there exists a path of zero resistance leading to a state in at least one recurrent communication class, (ii) any two states in the same recurrent communication class are connected by a path of zero resistance (in both directions), and (iii) for any recurrent communication class $X_{j}$ and states $x$ in $X_{j}$ and $y$ not in $X_{j}$ such that $P(\varepsilon)_{x y}>0$, the resistance of the transition from $\mathrm{x}$ to $\mathrm{y}$ is positive.

For two communication classes $X_{i}$ and $X_{j}$, since each $P(\varepsilon)$ is irreducible, it follows that there is a sequence of states $x_{1}, \ldots x_{k}$ with $x_{1}$ in $X_{i}$ and $x_{k}$ in $X_{j}$ such that the resistance of transition from $\mathrm{x}_{\mathrm{k}}$ to $\mathrm{x}_{\mathrm{k}+1}$ is defined by (iii) and finite. Denote this by $r\left(\mathrm{x}_{\mathrm{k}}, \mathrm{x}_{\mathrm{k}+1}\right)$. Let the resistance of transition

from $X_{i}$ to $X_{j}$ be the minimum over all such sequences of $\Sigma_{1}{ }^{K-1} r\left(x_{k}, X_{k+1}\right)$, and denote it by $r\left(X_{i}\right.$, $\left.\mathrm{X}_{\mathrm{j}}\right)$. 
Given a recurrent communication class $\mathrm{X}_{\mathrm{i}}$, an $i$-tree is a directed graph with a vertex for each communication class and a unique directed path leading from each class $j(\neq i)$ to $i$. The stochastic potential of a recurrent communication class $\mathrm{X}_{\mathrm{j}}$ is then defined by finding an i-tree that minimizes the summed resistance over directed edges, and setting the stochastic potential equal to that summed resistance.

Given any state $\mathrm{x}$, an $x$-tree is a directed graph with a vertex for each state and a unique directed path leading from each state $\mathrm{y}(\neq \mathrm{x})$ to $\mathrm{x}$. The resistance of $\mathrm{x}$ is then defined by finding an $\mathrm{x}$ tree that minimizes the summed resistance over directed edges.

The following theorem is a combination of Theorem 4 and Lemmas 1 and 2 in Young:

Theorem [Young (1993)]: Let P be the transition matrix associated with a stationary Markov process on a finite state space with a set of mutations $\{\mathrm{P}(\varepsilon)\}$ and with corresponding (unique) stationary distributions $\{\mathrm{m}(\varepsilon)\}$. Then $\mathrm{m}(\varepsilon)$ converges to a stationary distribution $\mathrm{m}$ of $\mathrm{P}$, and a state $\mathrm{x}$ has $\mathrm{m}_{\mathrm{x}}>0$ if and only if $\mathrm{x}$ is in a recurrent communication class of $\mathrm{P}$ which has a minimal stochastic potential. This is equivalent to $\mathrm{x}$ having minimum resistance.

Now let us return to the details of Theorem 1. Let us describe what must be true of any $\beta$ in $B(\mathrm{G})$. Consider a player in Group 1. It is easily checked that if $\mathrm{s}$ is a state where at least $\mathrm{q}$ of players in the Group 2 vote A, then regardless of the voting behavior of players in Group 1, the best response for the player anticipating $\mathrm{s}$ in $\mathrm{G}(\varepsilon)$ for small enough $\varepsilon$ is to vote $\mathrm{A}^{23}$ Similarly if fewer than $\mathrm{q}$ of the players in Group 2 vote $\mathrm{A}$, then the unique best response anticipating $\mathrm{s}$ in $\mathrm{G}(\varepsilon)$ for small enough $\varepsilon$ is to vote B. Thus, for small enough $\varepsilon$, any best-response correspondence maps states that have both groups electing to play A to a state where all players vote to play A, and similarly for B. In states where the groups are miscoordinating and one group is electing to play A and the other group is electing to play $\mathrm{B}$, any best response takes us to a situation where all players in the first group vote to play B and all players in the second group

\footnotetext{
${ }^{23}$ This is clear if the player were determining the action of his or her group. As the trembles of his group are independent of those of the other group, regardless of their play the player raises the probability of matching the other group by matching their play him or herself.
} 
vote to play A. Now consider the associated Markov process with small $\varepsilon$. Here there are three recurrent communication classes. They are a state where all players vote $\mathrm{A}$; a state where all players vote $\mathrm{B}$; and the two states where one group all votes A and the other group all votes $\mathrm{B}$ (these two states communicate with each other). We need only understand the resistance between these states to characterize the steady-state distribution as $\varepsilon$ goes to 0 . The resistance of leaving a state where all players vote $\mathrm{A}$ is $n-q+1$. The resistance of leaving a state where all players vote B is q.. The resistance of leaving a state where one group is all voting $\mathrm{A}$ and the other group is all voting $\mathrm{B}$ is $\min [n-q+1, q]$. We can build the trees as follows. Let us examine the case where $q$ is no more than $n / 2$ (the proof in the other case is analogous). Label our three communication classes $\mathrm{A}, \mathrm{B}$ and $\mathrm{A} / \mathrm{B}$ in the obvious way. Building a tree to class $\mathrm{A}$, we can point both class $\mathrm{B}$ and class $\mathrm{A} / \mathrm{B}$ to class $\mathrm{A}$. This leads to a total resistance of this tree is $2 q$. Building a tree to class $B$ requires a resistance of $\mathrm{q}$ from class $\mathrm{A} / \mathrm{B}$ that can be mapped to $\mathrm{A}$; but requires a resistance of $n-q+1$ to leave state A regardless of where it is pointed. This leads to a resistance of $n+1$. The same is true for a tree to class $\mathrm{A} / \mathrm{B}$. In both cases $2 q<n+1$, and so the state where all vote $\mathrm{A}$ is the only state in the limiting steady-state distribution. 


\section{Appendix B - Aggregated rates for adding links, by individual and game}

Table B1 - Games starting with 9's

\begin{tabular}{|c|c|c|c|c|}
\hline Participant \# & Mutual & Unilateral & 2 for 4 & 2 for 2 \\
\hline 1 & 0.00 & 0.53 & 0.00 & 0.00 \\
\hline 2 & 1.00 & 0.67 & - & 0.00 \\
\hline 3 & 0.00 & 0.87 & 0.00 & 0.00 \\
\hline 4 & 0.00 & 0.60 & - & 0.00 \\
\hline 5 & 0.00 & 0.93 & 0.00 & 0.00 \\
\hline 6 & 0.00 & 0.87 & 0.53 & 0.00 \\
\hline 7 & 0.00 & 1.00 & 0.00 & 0.00 \\
\hline 8 & 0.13 & 0.53 & - & 0.00 \\
\hline 9 & 0.00 & 0.87 & 0.00 & 0.00 \\
\hline 10 & 0.00 & 0.87 & 0.00 & 0.00 \\
\hline 11 & 0.00 & 0.73 & - & 0.00 \\
\hline 12 & 0.87 & 0.87 & - & 0.00 \\
\hline 13 & 0.07 & 0.93 & - & 1.00 \\
\hline 14 & 0.07 & 1.00 & - & 1.00 \\
\hline 15 & 0.00 & 1.00 & - & 1.00 \\
\hline 16 & 0.47 & 0.53 & 0.67 & 0.73 \\
\hline 33 & 1.00 & 1.00 & 1.00 & 1.00 \\
\hline 34 & 0.00 & 0.87 & - & 0.67 \\
\hline 35 & 0.20 & 0.27 & 0.60 & 1.00 \\
\hline 36 & 0.00 & 1.00 & - & 0.87 \\
\hline 37 & 0.00 & 1.00 & 0.93 & 0.93 \\
\hline 38 & 1.00 & 0.93 & 0.93 & 0.93 \\
\hline 39 & 0.27 & 0.40 & 0.60 & 0.07 \\
\hline 40 & 1.00 & 1.00 & - & 1.00 \\
\hline 41 & 0.00 & 0.53 & 0.67 & 0.87 \\
\hline 42 & 0.27 & 1.00 & 0.93 & 1.00 \\
\hline 43 & 0.00 & 0.67 & - & 0.00 \\
\hline 44 & 0.87 & 0.00 & - & 0.73 \\
\hline 45 & 0.87 & 0.93 & - & 1.00 \\
\hline 46 & 0.20 & 0.93 & - & 1.00 \\
\hline 47 & 0.87 & 0.53 & - & 1.00 \\
\hline
\end{tabular}




\begin{tabular}{|c|c|c|c|c|}
\hline 48 & 1.00 & 0.93 & 1.00 & 0.93 \\
\hline 65 & 0.00 & 0.00 & 0.93 & 0.00 \\
\hline 66 & 0.00 & 0.93 & - & 0.00 \\
\hline 67 & 0.00 & 0.40 & 0.00 & 0.00 \\
\hline 68 & 0.00 & 0.00 & - & 0.00 \\
\hline 69 & 0.87 & 1.00 & 1.00 & 0.00 \\
\hline 70 & 1.00 & 1.00 & 1.00 & 0.13 \\
\hline 71 & 0.00 & 0.87 & 0.00 & 0.73 \\
\hline 72 & 0.87 & 1.00 & - & 0.00 \\
\hline 73 & 0.00 & 0.80 & 0.33 & 0.07 \\
\hline 74 & 0.00 & 0.00 & 0.20 & 0.13 \\
\hline 75 & 1.00 & 1.00 & - & 0.80 \\
\hline 76 & 0.00 & 0.00 & - & 0.00 \\
\hline 77 & 0.00 & 0.93 & - & 0.00 \\
\hline 78 & 0.00 & 0.67 & - & 0.00 \\
\hline 79 & 0.00 & 1.00 & - & 1.00 \\
\hline 80 & 0.00 & 0.87 & 1.00 & 0.87 \\
\hline
\end{tabular}

Table B2 - Games starting with 8's

\begin{tabular}{|c|c|c|c|c|}
\hline Participant \# & Mutual & Unilateral & 2 for 4 & 2 for 2 \\
\hline 17 & 1.00 & 1.00 & 0.40 & 1.00 \\
\hline 18 & 1.00 & 1.00 & - & 1.00 \\
\hline 19 & 1.00 & 1.00 & 0.13 & 1.00 \\
\hline 20 & 1.00 & 1.00 & - & 0.20 \\
\hline 21 & 0.00 & 0.07 & 0.13 & 1.00 \\
\hline 22 & 0.00 & 0.07 & 0.00 & 0.00 \\
\hline 23 & 0.00 & 0.00 & 0.00 & 0.00 \\
\hline 24 & 0.00 & 0.00 & - & 1.00 \\
\hline 25 & 0.93 & 1.00 & 0.27 & 0.13 \\
\hline 26 & 0.00 & 0.93 & 0.07 & 0.00 \\
\hline 27 & 0.07 & 1.00 & - & 0.13 \\
\hline 28 & 0.20 & 1.00 & - & 1.00 \\
\hline 29 & 0.00 & 0.00 & - & 0.00 \\
\hline 30 & 0.60 & 0.87 & - & 0.60 \\
\hline 31 & 0.47 & 1.00 & - & 0.73 \\
\hline 32 & 0.27 & 1.00 & 0.13 & 0.93 \\
\hline 49 & 0.93 & 1.00 & 0.07 & 0.07 \\
\hline
\end{tabular}




\begin{tabular}{|c|c|c|c|c|}
\hline 50 & 0.00 & 1.00 & - & 0.93 \\
\hline 51 & 0.87 & 1.00 & 1.00 & 1.00 \\
\hline 52 & 0.00 & 1.00 & - & 1.00 \\
\hline 53 & 0.13 & 1.00 & 0.00 & 0.07 \\
\hline 54 & 0.13 & 1.00 & 0.07 & 1.00 \\
\hline 55 & 0.20 & 1.00 & 1.00 & 1.00 \\
\hline 56 & 0.07 & 0.00 & - & 0.07 \\
\hline 57 & 0.20 & 1.00 & 1.00 & 1.00 \\
\hline 58 & 0.13 & 1.00 & 1.00 & 1.00 \\
\hline 59 & 0.13 & 1.00 & - & 0.93 \\
\hline 60 & 0.93 & 1.00 & - & 0.13 \\
\hline 61 & 0.00 & 1.00 & - & 0.00 \\
\hline 62 & 0.00 & 0.93 & - & 0.00 \\
\hline 63 & 0.00 & 0.93 & - & 0.00 \\
\hline 64 & 0.07 & 0.93 & 0.00 & 0.07 \\
\hline 81 & 1.00 & 0.93 & 1.00 & 1.00 \\
\hline 82 & 0.53 & 1.00 & - & 1.00 \\
\hline 83 & 1.00 & 1.00 & 1.00 & 1.00 \\
\hline 84 & 0.33 & 0.00 & - & 0.93 \\
\hline 85 & 0.07 & 0.07 & 1.00 & 1.00 \\
\hline 86 & 0.00 & 0.00 & 0.00 & 1.00 \\
\hline 87 & 1.00 & 1.00 & 1.00 & 1.00 \\
\hline 88 & 0.00 & 1.00 & - & 1.00 \\
\hline 89 & 0.00 & 0.93 & 0.00 & 1.00 \\
\hline 90 & 0.93 & 0.00 & 0.00 & 1.00 \\
\hline 91 & 1.00 & 1.00 & - & 1.00 \\
\hline 92 & 0.00 & 0.07 & - & 1.00 \\
\hline 93 & 0.07 & 0.73 & - & 0.07 \\
\hline 94 & 0.40 & 1.00 & - & 0.27 \\
\hline 95 & 1.00 & 1.00 & - & 1.00 \\
\hline 96 & 0.00 & 1.00 & 0.13 & 1.00 \\
\hline
\end{tabular}




\section{Appendix C}

\section{Complete Individual Profiles Across Games}

\begin{tabular}{|c|c|}
\hline Profile - start with 9's & \# of occurrences \\
\hline $\mathrm{A}, \mathrm{A}, 0, \mathrm{~A}$ & 3 \\
\hline $\mathrm{A}, \mathrm{A}, \mathrm{A}, \mathrm{A}$ & 3 \\
\hline $\mathrm{A}, \mathrm{A}, 0, \mathrm{D}$ & 3 \\
\hline $\mathrm{A}, \mathrm{A}, \mathrm{A}, \mathrm{D}$ & 2 \\
\hline $\mathrm{A}, \mathrm{M}, 0, \mathrm{~A}$ & 1 \\
\hline $\mathrm{A}, \mathrm{D}, 0, \mathrm{~A}$ & 1 \\
\hline $\mathrm{M}, \mathrm{M}, \mathrm{A}, \mathrm{A}$ & 1 \\
\hline $\mathrm{D}, \mathrm{A}, \mathrm{A}, \mathrm{A}$ & 3 \\
\hline $\mathrm{D}, \mathrm{A}, 0, \mathrm{~A}$ & 7 \\
\hline $\mathrm{D}, \mathrm{A}, 0, \mathrm{D}$ & 5 \\
\hline $\mathrm{D}, \mathrm{A}, \mathrm{D}, \mathrm{A}$ & 1 \\
\hline D,A,D,D & 6 \\
\hline D,A,M,D & 1 \\
\hline $\mathrm{D}, \mathrm{M}, \mathrm{A}, \mathrm{A}$ & 1 \\
\hline $\mathrm{D}, \mathrm{M}, 0, \mathrm{D}$ & 2 \\
\hline $\mathrm{D}, \mathrm{M}, \mathrm{M}, \mathrm{D}$ & 1 \\
\hline D,M,D,D & 2 \\
\hline $\mathrm{D}, \mathrm{D}, 0, \mathrm{D}$ & 2 \\
\hline $\mathrm{D}, \mathrm{D}, \mathrm{A}, \mathrm{D}$ & 1 \\
\hline D,D,M,A & 1 \\
\hline $\mathrm{D}, \mathrm{D}, \mathrm{D}, \mathrm{D}$ & 1 \\
\hline All & 48 \\
\hline
\end{tabular}

\begin{tabular}{|c|c|}
\hline Profile - start with 8's & \# of occurrences \\
\hline $\mathrm{A}, \mathrm{A}, 0, \mathrm{~A}$ & 3 \\
\hline $\mathrm{A}, \mathrm{A}, \mathrm{A}, \mathrm{A}$ & 4 \\
\hline $\mathrm{A}, \mathrm{A}, 0, \mathrm{D}$ & 1 \\
\hline $\mathrm{A}, \mathrm{A}, \mathrm{M}, \mathrm{A}$ & 1 \\
\hline $\mathrm{A}, \mathrm{A}, \mathrm{D}, \mathrm{A}$ & 1 \\
\hline $\mathrm{A}, \mathrm{A}, \mathrm{D}, \mathrm{D}$ & 2 \\
\hline $\mathrm{A}, \mathrm{D}, \mathrm{D}, \mathrm{A}$ & 1 \\
\hline $\mathrm{M}, \mathrm{A}, 0, \mathrm{~A}$ & 2 \\
\hline $\mathrm{M}, \mathrm{A}, 0, \mathrm{M}$ & 1 \\
\hline $\mathrm{M}, \mathrm{A}, 0, \mathrm{D}$ & 1 \\
\hline $\mathrm{D}, \mathrm{A}, \mathrm{A}, \mathrm{A}$ & 3 \\
\hline $\mathrm{D}, \mathrm{A}, 0, \mathrm{~A}$ & 5 \\
\hline $\mathrm{D}, \mathrm{A}, 0, \mathrm{D}$ & 6 \\
\hline $\mathrm{D}, \mathrm{A}, \mathrm{D}, \mathrm{A}$ & 4 \\
\hline $\mathrm{D}, \mathrm{A}, \mathrm{D}, \mathrm{D}$ & 3 \\
\hline $\mathrm{D}, \mathrm{D}, 0, \mathrm{~A}$ & 3 \\
\hline $\mathrm{D}, \mathrm{D}, \mathrm{A}, \mathrm{A}$ & 1 \\
\hline $\mathrm{D}, \mathrm{D}, 0, \mathrm{D}$ & 2 \\
\hline $\mathrm{D}, \mathrm{D}, \mathrm{D}, \mathrm{A}$ & 2 \\
\hline $\mathrm{D}, \mathrm{D}, \mathrm{D}, \mathrm{D}$ & 2 \\
\hline All & 48 \\
\hline
\end{tabular}

The order of the games in both profiles is: mutual, unilateral, 2 for 4 , and 2 for 2 . 
"A" means an individual chose to add a link 10 of more times (of 15 in the respective segment), "D" means an individual chose to not add a link 10 or more times, "M" means an individual chose both actions at least six times, and "0" means an individual had no choice in the game 


\section{Appendix D - Experimental Instructions (Start with 9's)}

Welcome to our experiment. You will receive $\$ 5$ for showing up, in addition to your earnings from the session.

There will be a total of 60 periods in the session. You will be paired with a group of people (and your position in the group will stay the same) for 15 periods, and then your pairing will change for the next 15 periods, etc.

Payoffs for each person are determined by the links that exist in the network below at the end of a period. Your group begins with the following links:

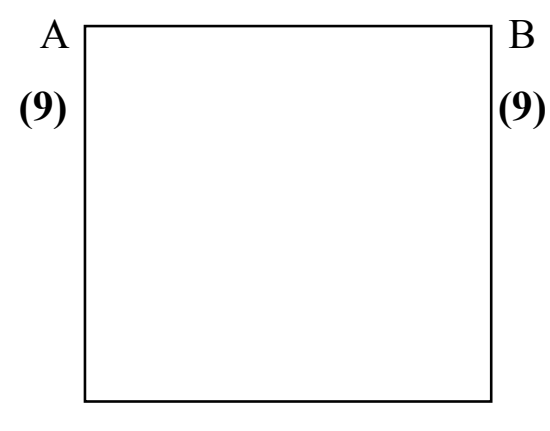

If this network is in place at the end of the period, then each of $\mathrm{A}, \mathrm{B}, \mathrm{C}$, and $\mathrm{D}$ would receive 9 units, as is indicated by the bold number in parentheses below each letter.

Some or all of the people in the network will simultaneously indicate on their computer their choice concerning whether or not to add a link to the person diagonally opposite. There are 4 different cases, and you will make choices in each case for 15 periods during the session: 
1) People are in 4-person groups. Consider the people diagonally across: A link is added if at least one of these two people wishes to add it.

2) People are in 4-person groups. Consider the people diagonally across: A link is added if and only if both of these two people wish to add it.

3) People are in 4-person groups; however, only two of these people (not diagonally across from each other) choose whether to add links. Each person's decision is implemented and two silent participants in the group receive payoffs according to these choices.

4) People are in 2-person groups, so that each person controls 2 vertices. If a person chooses to add a link, it is added and he or she receives the payoffs from one vertex.

You will always know which case applies to your decision before you make your decision.

There are four possible networks that could result from the process of adding or not adding links. The first is the network pictured above, where there are no changes. The other three possibilities arise if at least one link is added. These networks, and the corresponding payoffs to the participants are as follows:

A
(8)

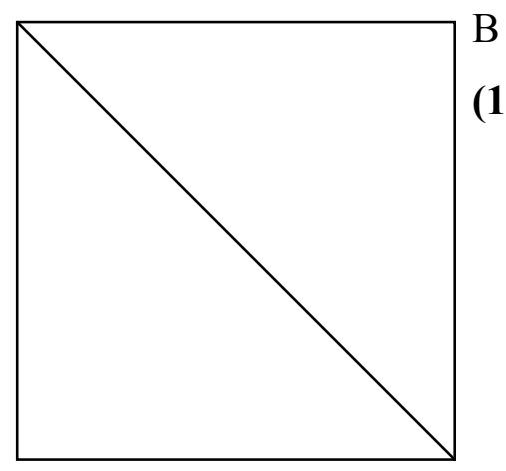

(1)

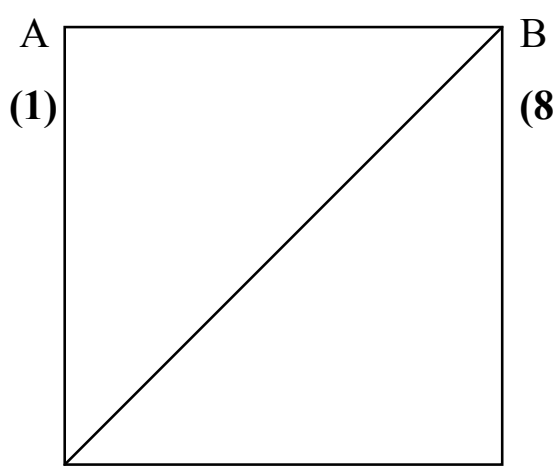

$\mathrm{C}$

(1)
$\mathrm{D}$

(8)
$\mathrm{C}$

(8)
B

(8)

$\mathrm{D}$

(1) 


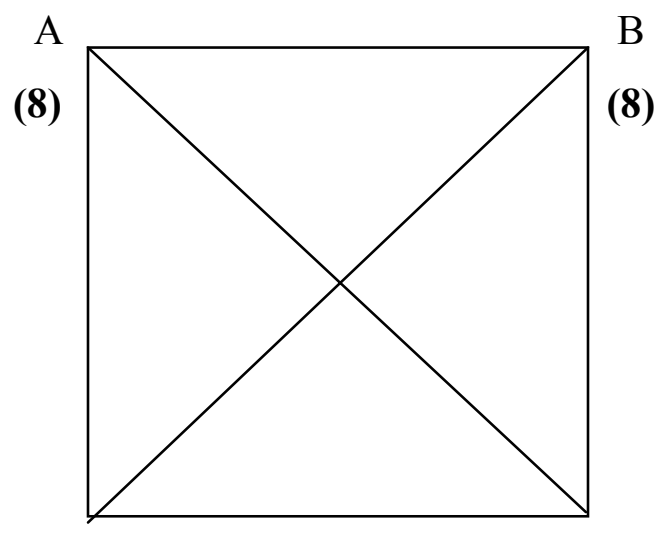

C

D

(8)

(8)

The diagrams show that if exactly one diagonal link is included in the final network, the people connected by the link receive 8 units and the people not connected by the diagonal link receive 1 unit.

If both diagonal links are included in the final network, then everyone in the network receives 8 units.

We will randomly choose one period from each of the 15-period blocks for payment, so that only four periods will actually count towards monetary payoffs. These periods will be chosen at the end of the session. We will add up your payoffs from these four periods and convert them to actual dollars at the rate of $\$ 0.30$ for each unit.

At the end of the experiment, we will pay each participant individually and privately.

We encourage you to ask questions about the instructions by raising your hand.

Thank you again for your participation in our research. 


\section{References}

Bala, V. and S. Goyal (2000) “A Non-cooperative Model of Network Formation,” Econometrica, 68, 1181-1229.

Blinder, A. and J. Morgan (forthcoming), “Are Two Heads Better than One? An Experimental Analysis of Group versus Individual Decision Making," Journal of Money, Credit, and Banking.

Bornstein, G., U. Gneezy, and R. Nagel (2002), “The Effect of Intergroup Competition on Group Coordination: An Experimental Study," Games and Economic Behavior, 41, 1-25.

Carlsson, H. and E. van Damme (1993), "Global Games and Equilibrium Selection," Econometrica, 61, 989-1018.

Cason, T. and V.-L. Mui (1997), "A Laboratory Study of Group Polarisation in the Team Dictator Game," Economic Journal, 107, 1465-1483.

Charness, G. (2000), "Responsibility and Effort in an Experimental Labor Market," Journal of Economic Behavior and Organization, 42, 375-384.

Chwe, M. (1994), “Farsighted Coalitional Stability,” Journal of Economic Theory, 63, 299-325.

Cooper, D. and J. Kagel (2003), “Are Two Heads Better Than One? Team versus Individual Play in Signaling Games," mimeo.

Cox, J. (2002), “Trust, Reciprocity, and Other-regarding Preferences: Groups vs. Individuals and Males vs. Females," in Zwick and Rapoport, eds., Advances in Experimental Business Research, 331-350, Dordrecht: Kluwer Academic Publishers.

Duggan, J. (2001), “Non-cooperative Games Among Groups,” mimeo. 
Dutta, B., S. Ghosal, and D. Ray (2003) "Farsighted Network Formation," mimeo: University of Warwick and NYU.

Fischbacher, U. (1999), "z-Tree - Zurich Toolbox for Readymade Economic Experiments Experimenter's Manual," Institute for Empirical Research in Economics, University of Zurich.

Foster, D. and H. P. Young (1990), "Stochastic Evolutionary Game Dynamics," Theoretical Population Biology, 38, 229-232.

Fréchette, G., J. Kagel, and S. Lehrer (2003), "Bargaining in Legislatures: An Experimental Investigation of Open versus Closed Amendment Rules," American Political Science Review, 97, 221-232.

Harsanyi, J. and R. Selten (1988), A General Theory of Equilibrium Selection in Games, Cambridge: MIT Press.

Jackson, M.O., "A Survey of Models of Network Formation: Stability and Efficiency," forthcoming in Group Formation in Economics; Networks, Clubs and Coalitions, edited by Gabrielle Demange and Myrna Wooders, Cambridge University Press.

Jackson, M.O. and A. van den Nouweland (2001), "Strongly Stable Networks,"' forthcoming in Games and Economic Behavior.

Jackson, M.O. and A. Watts (2002), "The Evolution of Social And Economic Networks," Journal of Economic Theory, 106, 265-295.

Jackson, M.O. and A. Wolinsky (1996), “A Strategic Model of Social and Economic Networks," Journal of Economic Theory, 71, 44-74. 
Kandori, M., G. Mailath, and R. Rob (1993), "Learning, Mutation, and Long Run Equilibria in Games, Econometrica, 61, 29-56.

Kocher, M. and M. Sutter (forthcoming), “The Decision maker Matters; Individual versus Group Behaviour in Experimental Beauty-Contest Games," Economic Journal.

Morris, S., D.M. Frankel, and A. Pauzner (2001), "Equilibrium Selection in Global Games with Strategic Complementarities," Cowles Foundation Working Paper no. 1336.

Myerson, R. (1990), Game Theory: Analysis of Conflict, Harvard University Press: Cambridge MA.

Page, F. and M. Wooders, and S. Kamat (2001), "Networks and Farsighted Stability," mimeo: University of Warwick.

Pantz, K. and A. Ziegelmeyer (2003), “An Experimental Study of Network Formation,” mimeo: Max Planck Institute.

Sherif, M. (1966), In Common Predicament: Social Psychology of Intergroup Conflict and Cooperation, Boston: Houghton-Mifflin

Siegel, S. and N. Castellan, Jr. (1988), Nonparametric Statistics for the Behavioral Sciences, Boston: McGraw-Hill.

Tajfel, H. (1982), Social Identity and Intergroup Relations, Cambridge: Cambridge University Press

Young, H.P. (1993), “The Evolution of Conventions,” Econometrica, 61, 57-84.

Young, H.P. (1998), Individual Strategy and Social Structure, Princeton: Princeton University Press. 